\title{
Música, género e identidad: fandangos y coplas del Romero
}

\author{
Music, Gender and Identity: \\ Fandangos and Coplas del Romero
}

\author{
Herminia Arredondo Pérez ${ }^{1}$ \\ Universidad de Huelva \\ Francisco J. García Gallardo ${ }^{2}$ \\ Universidad de Huelva
}

\section{RESUMEN}

Este artículo explora la relación de la música y el género en el contexto de una manifestación ritual festiva en Almonaster la Real, localidad de la provincia de Huelva. Durante la celebración de la Cruz de Mayo y en los actos preliminares a la fiesta, las mujeres cruceras protagonizan el ritual e interpretan las coplas del Romero y varios estilos de fandangos de la Cruz. Analizamos las implicaciones del género en esta actividad musical, en las tradiciones interpretativas, repertorio, formas expresivas y sus significados para las mujeres de las dos cruces o hermandades de Almonaster. Examinamos cómo esta práctica musical contribuye a afirmar y articular ideas, modelos y roles específicos relacionados con el género, que expresan y configuran la identidad de grupo e identidad personal de las mujeres en este contexto.

Palabras clave: Música tradicional; Género; Fandangos; Cruz de Mayo; Identidad.

\section{SUMMARY}

This article explores the relationship between music and gender in the context of a festive ritual manifestation in the town of Almonaster la Real (Huelva). During the celebration of the Cross of May and in the acts prior to the feast day, the women cruceras lead the ritual and play the music that takes place in it, coplas del Romero and several styles of fandangos de la Cruz. We analyse the implications of gender in this musical activity, interpretive traditions, repertoire, expressive forms and meanings for the women of the two crosses or Almonaster brotherhoods. We examine how this musical practice contributes to affirming and articulating specific ideas, models and roles related to gender, that express and shape the group identity and personal identity of women in this context.

Keywords: Traditional Music; Gender; Fandangos; May Cross; Identity.

\footnotetext{
${ }^{1}$ Correo electrónico: herminia@uhu.es. ORCID iD: <https://orcid.org/0000-0002-8694-5499>.

${ }^{2}$ Correo electrónico: fgarcia@uhu.es. ORCID iD: <https://orcid.org/0000-0003-3106-1765>.
} 


\section{INTRODUCCIÓN}

Actualmente el género ha llegado a concebirse como factor esencial en la comprensión e interpretación de la vida y la conducta humana en todas las sociedades. Como categoría teórica se refiere a construcciones culturales, ideológicas y discursivas de los sexos biológicos en contextos históricos y culturales específicos (Hanna 1988; Ortner 1974; Ortner y Whitehead 1981). También, en un sentido amplio, constituye una perspectiva de estudio que ha permitido abrir un fructífero espacio teórico para la interpretación de significados del mundo social y simbólico en distintas manifestaciones de la cultura y de la vida de las personas (Evans 1997).

En la investigación musical, el punto de vista del género es considerado un agente decisivo. Desde hace mucho tiempo la información sobre biografías de mujeres músicas, repertorios y actividades musicales vinculadas a ellas, ha formado parte de algunos trabajos de musicología y etnomusicología. Sin embargo, la interpretación desde el punto de vista del feminismo, primero, y de la dinámica de género, después, no ha sido tenida en cuenta hasta hace tan solo unas décadas. A partir de los años ochenta del siglo pasado, como señala Ellen Koskoff (1987: 2), un mayor número de investigadoras del campo de la música comenzaron a ser cada vez más conscientes "del impacto de la estructura de género en la sociedad en todos los tipos de comportamiento". Esto supuso una nueva actitud crítica en las aproximaciones y modelos teóricos, tanto en los nuevos estudios como en la revisión de trabajos anteriores. Marcia Herdorn expresaba sobre esto:

El estudio de la música y el género no es simplemente una cuestión de descripción de dominios, estilos y tipo de interpretaciones típicos de músicos hombres y mujeres en marcos sociales particulares. Más bien, centrarse en el género como estrategia metodológica, nos lleva a examinar temas, problemas e interrelaciones desde un nuevo punto de vista (Herdorn 1990: 11).

Por esos años, otras autoras comenzaron a abordar líneas de investigación desde la teoría crítica del feminismo y desde nuevos puntos de vista en relación al género: condiciones sobre la participación femenina en actividades musicales, ideologías y construcciones culturales del género; relación de la música, género y sexualidad con dominios de poder, de agencia política y de búsqueda de valor social (Robertson 1987; Koskoff 1987); semiótica musical del género, construcciones musicales del género y la sexualidad (McClary 1991); papel de los roles y relaciones de género en la actividad musical (Herdorn y Ziegler 1990); género y creación de un canon musical (Citron 1993), entre otras muchas cuestiones. Desde los años noventa hasta la actualidad, en estudios históricos así como en los de todo tipo de manifestaciones musicales del mundo de cualquier época y lugar, la musicología crítica feminista y los estudios de música y género posibilitan una amplia y heterogénea variedad de aportaciones que siguen generando interesantes debates.

En este texto presentamos una aproximación a una tradición musical de nuestro entorno cercano, la música y el cante de fandangos en una localidad de la provincia de Huelva, incorporando la perspectiva de género a categorías teóricas y analíticas de la musicología y etnomusicología, disciplinas desde las que se plantea esta investigación ${ }^{3}$.

\footnotetext{
${ }^{3}$ Este texto forma parte del trabajo de investigación llevado a cabo para la tesis doctoral (en fase de finalización) sobre música, mujer y fandangos en la provincia de Huelva, de la profesora
} 
Entre la variedad y riqueza de manifestaciones de fandangos que se mantiene en la provincia de Huelva (Romero Jara 2002), el cante de los fandangos en la localidad serrana de Almonaster la Real constituye un caso relevante y singular para estudiar la relación de música, género e identidad. En este pueblo, situado a unos cien kilómetros de la capital onubense y que cuenta con un rico patrimonio natural, histórico y cultural, durante la celebración de una de sus festividades más importantes, las Cruces de Mayo, se interpretan un gran número de fandangos y otras coplas en todos los actos de celebración festiva. Las coplas del Romero y los fandangos de la Cruz son cantados y tocados con la pandereta por las mujeres de Almonaster en una fiesta de protagonismo exclusivamente femenino. Se trata de una tradición, un repertorio y unas prácticas de interpretación musical en las que el género articula las cuestiones más relevantes. Las mujeres se ocupan de la celebración y preparación del ritual, interpretan la música y expresan públicamente modelos locales de identidad de género.

Este texto explora las dinámicas de las relaciones de género en esta práctica musical contextualizada en la celebración festiva de la localidad. Cómo cuestiones de género se encuentran inmersas en discursos, actividades musicales y prácticas de interpretación de fandangos y coplas asociadas a mujeres en este contexto particular. Asimismo, analizamos qué tipo de significaciones conllevan asociadas y qué identidades sociales y personales son negociadas y construidas. Qué experiencias y expectativas crean en la interpretación musical las mujeres protagonistas de las Cruces en Almonaster.

\section{CRUCES DE MAYO: AFIRMANDO LA TRADICIÓN FEMENINA}

La celebración de la Cruz en torno al día tres de mayo ha formado parte de los modos de vida y de la cultura tradicional en las sociedades campesinas de Europa occidental. En nuestro país constituía, inserta en el calendario anual, una de las grandes fiestas desde que la Iglesia Católica cristianizara y sincretizara anteriores celebraciones y cultos paganos del mes de mayo con la exaltación del símbolo cristiano de la cruz (García Fernández 2004; Rodríguez Becerra 1999 y 2004: 58). La fiesta contaba, como han recogido numerosos estudios históricos, de antropología y cultura popular, con una amplia variedad de manifestaciones que comprendían desde elementos de celebración religiosa a un gran número de expresiones en torno a ritos paganos de renovación de la naturaleza (Caro Baroja 1979). En Andalucía conserva, en la actualidad, su carácter lúdico y una fuerte raigambre popular; y aún se desarrolla con gran diversidad de rituales en los que siempre se encuentra presente la cruz latina ornamentada junto a otras celebraciones precristianas de la primavera (Rodríguez Becerra 2004: 59-69).

\footnotetext{
Herminia Arredondo Pérez y dirigida por el Dr. Francisco J. García Gallardo en la Universidad de Huelva. El relato y las descripciones que presentamos en este trabajo han sido elaboradas a partir de nuestra participación en la fiesta, de la observación directa, la escucha atenta de la interpretación musical, las entrevistas con los participantes y protagonistas en las Cruces, así como a partir de la transcripción y análisis musical, del estudio y análisis de la documentación tanto escrita como audiovisual obtenida en nuestro propio trabajo de campo y del consultado y proveniente de otras fuentes.
} 
Entre toda esta variedad de formas de celebración, un rasgo permanece ligado a la fiesta: su vinculación al dominio femenino. La mujer como protagonista simbólica y real de la fiesta de la Cruz de Mayo constituye uno de los elementos definitorios más comunes en muchos lugares.

Esto no resulta extraño si repasamos desde una perspectiva histórica la estrecha relación que la mujer tiene en la sociedad tradicional con aspectos devocionales de la cruz como símbolo religioso, con su protección, adoración, rezo o canto, manifestación de fervor religioso o de religiosidad popular. La devoción a la cruz se generalizó desde hace siglos en muchos lugares de nuestro país llegando a tener un gran arraigo en esta parte de Andalucía ${ }^{4}$. Su símbolo, una cruz sin imagen, prosperó en todos los sitios —en casas, encrucijadas de calles y caminos, entrada y salida de núcleos de población - como elemento protector contra el mal. A la vez se extendió como atributo devocional y objeto de culto dando lugar a distintas formas de celebración con sentido religioso, pero no litúrgico5. En Almonaster, como en otros pueblos de la provincia, las mujeres están comprometidas con todo lo que tiene que ver con la cruz como elemento devocional y símbolo de tradición cultural. Se encargan del cuidado, custodia y adoración de una antigua cruz que se conserva en el templo religioso, de los momentos de su culto, de la conservación de las otras cruces de exterior que hay en el pueblo, de los elementos del ritual de la fiesta, de su celebración y del canto de las coplas de alabanza a la cruz, transmitiendo a las jóvenes generaciones toda esta experiencia históricamente vinculada a la mujer.

Al mismo tiempo, como hemos comentado, la Cruz de Mayo mantiene en este contexto tradiciones relacionadas con antiguas celebraciones paganas de la estación primaveral. Mayo, época de esplendor de la primavera, ha sido asociado por la cultura popular a una gran variedad de cultos en torno a la fertilidad, la mujer, el amor, la exaltación de la vida, la juventud y la regeneración de la naturaleza: en las fiestas de la maya o mayas, del árbol mayo, las enramadas y los ramos entre otras (Caro Baroja 1979; Eliade 1972 y 1974; Velasco 1982). Las sociedades rurales tradicionales marcaron este tiempo de esplendor y fuerza vital de la naturaleza con acciones rituales, símbolos y creencias que vinculan la fecundidad y regeneración natural de la tierra a la cosmovisión del entorno, al ciclo de la vida humana y a concepciones de la propia cultura. La mujer, por analogía a su función biológica reproductora, aparece culturalmente asociada de una manera especial a los ritos y ceremonias del mes de mayo; como en las antiguas fiestas de las mayas ${ }^{6}$ en las que, representada en la mu-

\footnotetext{
${ }^{4}$ Alberto del Campo y Ana Corpas (2005: 388-406) en su estudio sobre el mayo festero señalan que en Andalucía las hermandades y cofradías de la Vera Cruz proliferaron a partir del siglo XVI y en Huelva en concreto, han existido históricamente poderosas hermandades de Vera Cruz.

${ }^{5}$ En el Archivo Municipal de Almonaster, leg. 724, se recoge la existencia de una Cofradía de la Vera Cruz al menos desde el siglo XVII. Aparece en un pleito civil de 1678 (Barroso 1996; Vázquez 1997).

${ }^{6}$ Referencias a la fiesta de la maya o mayas en fuentes históricas y estudios etnográficos en nuestro país, describen costumbres que consisten principalmente en juegos o ceremonias que llevan a cabo las niñas y/o jóvenes para elegir a la más hermosa de ellas — la maya-, engalanarla, coronarla o rodearla de flores, colocarla en un tálamo, trono o mesa, así como en preparar un altar para la fiesta, realizar matrimonios simbólicos, interpretar cantos, bailes, prácticas petitorias u otras diversas variantes en distintos lugares (Caro Baroja 1979; González y Mele 1944).
} 
jer joven o niña, ritualiza la concepción tradicional de su rol social, el tránsito de niña, joven, virgen, a novia y madre. Además de las festividades de las mayas ${ }^{7}$, otras expresiones y ritos paganos han dejado su reminiscencia en la celebración de la Cruz de Mayo.

En la provincia de Huelva, los rituales y simbolismos relacionados con la naturaleza, los valores asociados a la fertilidad y el protagonismo de una pareja joven son comunes a numerosas Cruces (Jiménez de Madariaga 2004 y 2011; Rodríguez Becerra 1999 y 2004).

En Almonaster, la puesta en escena del ritual y la fiesta pone de relieve con excepcional plasticidad visual la exuberancia de la naturaleza en el mismo núcleo urbano que se prepara en su espacio de celebración como si fuese una extensión del entorno natural. En él todo se embellece - la cruz, las calles, los salones de hermandad- con una gran variedad de adornos y elementos vegetales. También, celebrando la renovación del ciclo de la vida y la fecundidad, la protagonista de la fiesta es una mujer joven — la mayordoma - elegida cada año y acompañada simbólicamente del mozo —o mayordomo- como única figura masculina que participa en el ritual. Pareja joven que simboliza de acuerdo a construcciones culturales de la feminidad y la masculinidad de la sociedad patriarcal, el valor de la juventud, la fertilidad y el rol reproductivo en la renovación de la vida, reforzando la identidad biológica de ambos sexos en la sociedad. Las propias cruceras responsables de desplegar el ritual y cortejo de la Cruz cantando su música son también muchachas jóvenes.

Todavía hoy, celebraciones festivas como esta siguen manteniendo formas simbólicas de celebración ritual en su contexto local marcadas por antiguas tradiciones, formas de vida y valores sociales en base a una distinción de género. Las Cruces en Almonaster representan un ejemplo enfatizado del vínculo de una tradición cultural con la mujer, y de manera especial, con la mujer joven.

\section{LAS CRUCES EN ALMONASTER}

Las Cruces tienen lugar a principios de mayo, pero su periodo de puesta en marcha comienza aproximadamente un mes antes. Cada año, al llegar abril, se inician los preparativos de la fiesta en las noches de las Flores cuando las cruceras se reúnen en sus salones o casas de hermandad para la preparación de objetos decorativos y elementos simbólicos del ritual. Para poner a punto los instrumentos musicales, estandartes y varas, repasar el canto, así como para confeccionar minuciosamente las flores de papel que adornarán la $\operatorname{cruz}^{8}$, los arcos de $c h u b a r b a^{9}$ y las cadenetas de las calles.

Las veladas de las noches de las Flores constituyen un espacio privilegiado de estrecha relación social entre las mujeres que componen cada cruz, hermandad ${ }^{10} \mathrm{O}$

\footnotetext{
${ }^{7}$ Para Rodríguez Becerra (2004: 59-62) la asociación de las mayas con la fiesta de la Cruz es especialmente llamativa en Andalucía, persistiendo hasta la primera mitad del siglo XX.

${ }^{8}$ Cruz de exterior, de hierro forjado, construida sobre la estructura de un pilar.

9 Chubarba, chusbarba, jusbarba: un arbusto con el que se adorna la cruz.

${ }^{10}$ En Almonaster hay dos hermandades en la Cruz: Hermandad de la Santa Cruz del Llano y Hermandad de la Santa Cruz de la Fuente.
} 
grupo unido principalmente por vínculos familiares y de vecindad. Se trata de reuniones mayoritariamente femeninas ${ }^{11}$, íntimas, en las que mujeres se asocian para encargarse de la economía doméstica de la hermandad, elaborar los preparativos materiales de la celebración, organizar los actos repartiendo trabajo y responsabilidades. También en ellas se debate, se acuerdan cuestiones en relación al desarrollo de la fiesta ese año, se repasa el canto. Todo ello representa el comienzo de un compromiso explícito de la mujer con esta tradición femenina. Las Flores funcionan como auténtico espacio de enculturación donde niñas y jóvenes van asimilando el papel de la mujer en la fiesta y en la comunidad. Posibilitan el acceso al conocimiento de muchos aspectos de la cultura local — cómo se disponen y se desarrollan las prácticas, los ritos festivos, la música-, a la vez que asimilan concepciones, modelos de comportamiento femeninos y valores como el compromiso con la tradición y la colaboración en el grupo y en la comunidad. Como en las Flores, se accede a estas vivencias de la fiesta de la Cruz a través de la observación directa y el seguimiento de la propia celebración o participando a una edad temprana en el Romero infantil, réplica abreviada de la Cruz.

Las cruceras mayores con más experiencia y que viven todo el año en el pueblo son las encargadas de transmitir a las muchachas jóvenes y niñas el conocimiento de esta tradición heredada, encargándose de su conservación, continuando así con el papel de preservadoras y transmisoras de la tradición cultural y musical local.

Al mismo tiempo, las reuniones de las Flores, contribuyen a afianzar las relaciones intergeneracionales y vínculos afectivos entre las mujeres. La distribución de tareas y otras decisiones del grupo se toman de forma colaborativa, el trabajo se distribuye y la música se interpreta conjuntamente, reforzando aún más los lazos afectivos del grupo. Si las generaciones mayores aportan su compromiso y experiencia, las muchachas jóvenes se implican en los preparativos y en la celebración festiva de muy diversas formas. Y aunque en distinto grado, estas asumen el esfuerzo necesario para que la Cruz no decaiga. Por ejemplo, ofreciéndose como mayordoma, vistiéndose de serrana, participando en el ritual y cantando, interviniendo en el pique entre cruces, así como involucrándose en la enseñanza de las pequeñas o jóvenes serranas. Una crucera joven nos comentaba:

Para mí las Cruces es algo especial. Esté donde esté, yo siempre vuelvo a las Cruces, y como dice el fandango [canta]:

Ahora y siempre lo diré.

Soy de la calle la Fuente,

por muy lejos que me vaya

de la Fuente me acordaré (Ángeles Ventura, entrevista personal, feb. 2006).

Después de los preparativos del mes de abril y hasta la celebración de la fiesta de la Cruz en el primer fin de semana de mayo, se suceden una serie de actos establecidos $^{12}$ : Domingo de chubarba, Tarde de las Flores y Noche de los Pinos.

\footnotetext{
${ }^{11}$ También forman parte como socios de la hermandad, jóvenes y hombres del pueblo que participan en esta fiesta.

${ }^{12}$ Sobre el proceso ritual y la organización social de Almonaster a finales de los sesenta y principios de los setenta del siglo XX, puede verse La gente de Santa Eulalia. Almonaster la Real (Huelva). Estructura y proceso ritual en una comunidad andaluza (Aguilera 1995).
} 
Finalizando abril, en el Domingo de chubarba, después de haber recogido esta planta con la que se adornará la cruz, cada una de las dos hermandades entra en procesión por una parte distinta del pueblo portando la carga y cantando coplas.

A la semana siguiente, el primer sábado de mayo en la Tarde de las Flores y la Corta del romero de nuevo cada hermandad vuelve a entrar en el pueblo cantando y llevando en este caso ramas de chopo y romero. En este acto se presenta además a la mayordoma y diputadas o acompañantes de ese año [Figura 1]. En la madrugada del sábado al domingo tiene lugar la Noche de los Pinos cuando las hermandades rondan por el pueblo dirigiéndose los fandangos de pique. Finalmente, el domingo comienza la celebración propiamente dicha de las Cruces, el día grande.

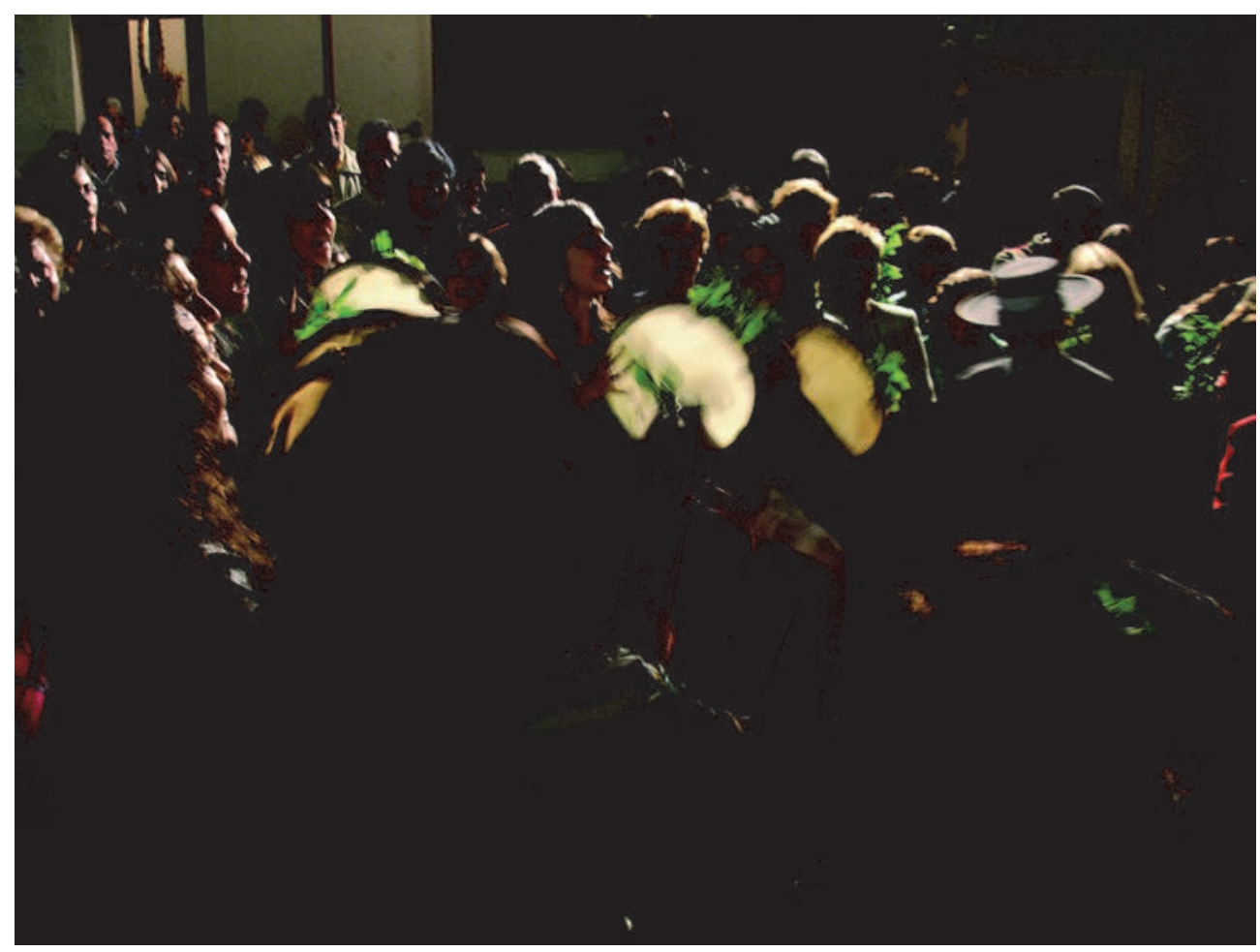

FIgurA 1.-Cantando fandangos en la Tarde de las Flores y Corta del romero. Foto de Herminia Arredondo y Francisco J. García Gallardo

En Almonaster se utiliza la denominación plural de cruces para referirse a las dos que forman parte de esta manifestación. Como en otras localidades de Huelva, la organización de la fiesta se establece en torno a dos o más cruces poniendo de este modo en juego el sentido de identidad grupal o semicomunal y territorial (Campo y Corpas 2005; Jiménez de Madariaga 2004 y 2011; Rodríguez Becerra 2004). Celeste Jiménez indica que la sectorialización del espacio físico y social hace que cada cruzhermandad constituya un grupo diferenciado que compite por superar a la contraria en todos los aspectos y, asimismo, todo el proceso festivo va sucediéndose a modo 
de cruces "de mitades" (Jiménez de Madariaga 2004: 106) o "sistema dual de hermandades" (Moreno Navarro 1982: 83-84 y 1985: 147-151). En Almonaster cada cruz representa el elemento físico que funciona como símbolo conmemorado en el ritual. También representa un colectivo humano que aglutina a un grupo de vecinos y de familias unido funcionalmente, que se esfuerza en mantener su identidad grupal, y que se encuentra localizado en una parte diferente del pueblo: la Cruz de la Fuente situada en la parte más baja, en un cruce entre varias calles, y la del Llano en una amplia plaza de la parte alta [Figuras 2 y 3].

El ritual de la fiesta se organiza con un orden en el que los actos acontecen en los dos grupos sin solaparse, de acuerdo a un protocolo establecido, consensuado por todos e institucionalizado, ayudando a mantener el equilibrio social. Por la mañana del Día de la Cruz, la hermandad de la Fuente es la primera en iniciar sus actos ceremoniales y por la tarde, en una secuencia similar, le sigue la del Llano. El protocolo cuenta con momentos destacados de entrada en el pueblo, de recorrido y visitas a determinados lugares emblemáticos así como de reunión en torno a la Cruz.

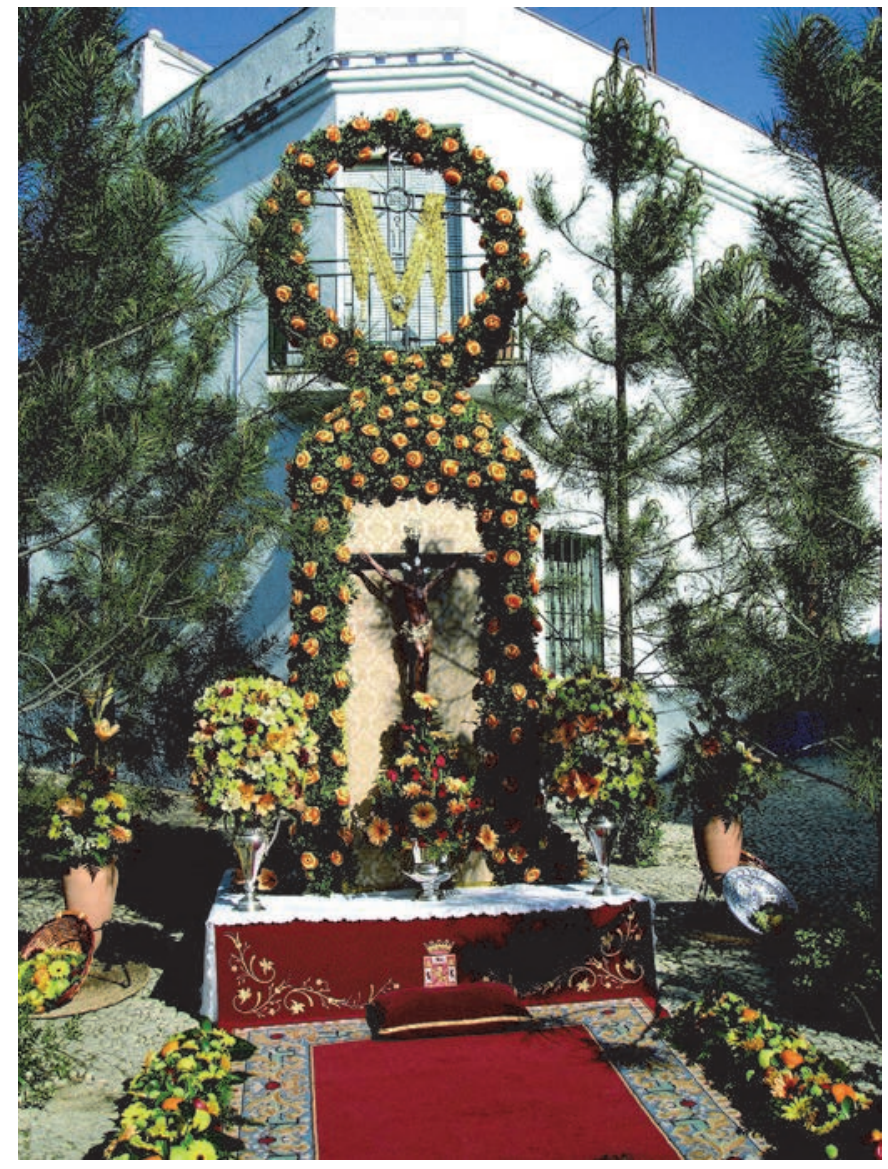

FiguRA 2.-Cruz de la Fuente. Foto de Herminia Arredondo y Francisco J. García Gallardo 


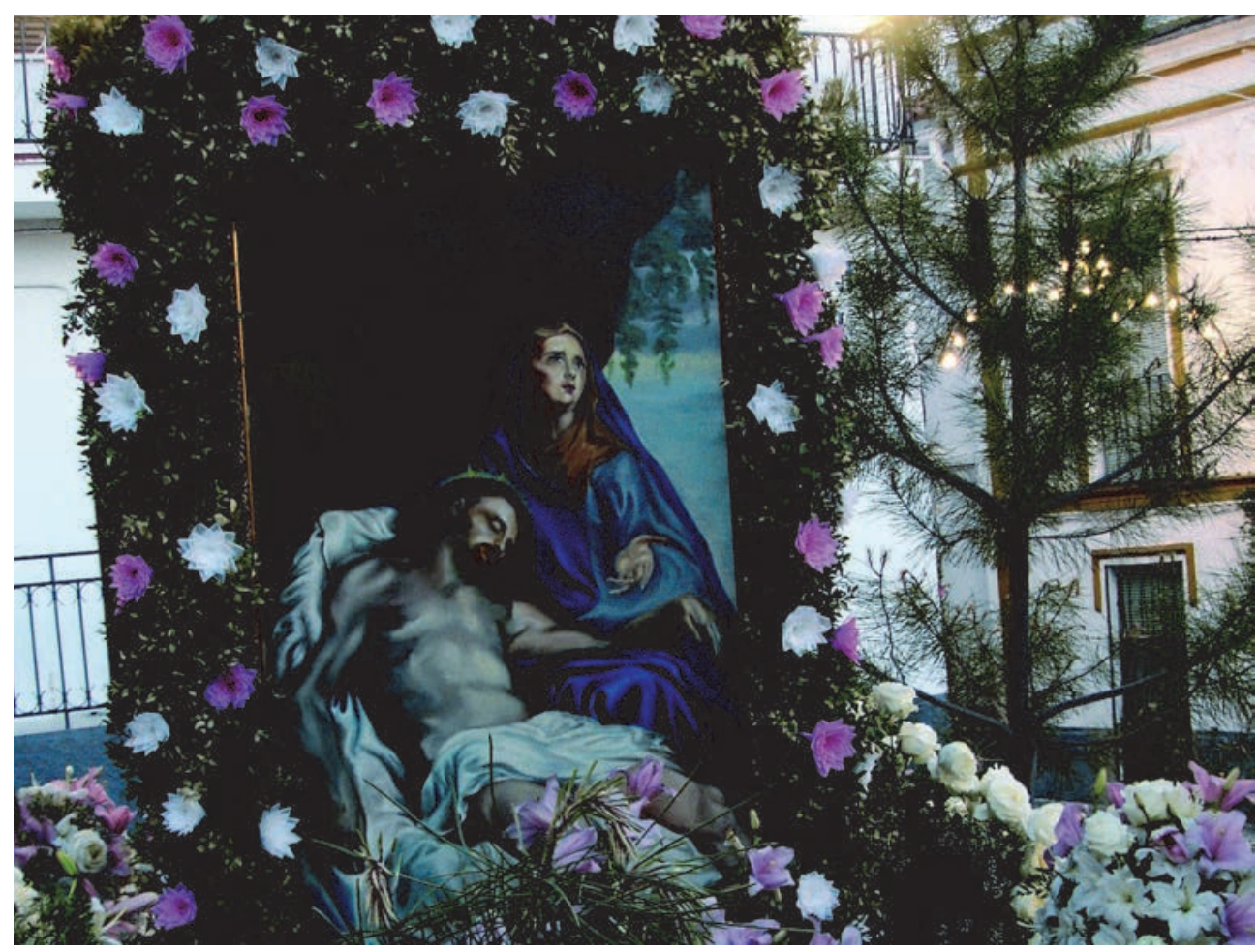

FIguRA 3.-Cruz del Llano. Foto de Herminia Arredondo y Francisco J. García Gallardo

El sentimiento de pertenencia a una sola Cruz, el Llano o la Fuente, es transmitido principalmente de las mujeres cruceras a sus hijas e hijos. Otras circunstancias pueden crear ese vínculo, e incluso hay familias en las que varios de sus miembros pertenecen a una u otra, pero las mujeres suelen afiliarse a cada grupo por tradición o herencia materna, como en una especie de genealogía matrilineal. La organización principal de las dos hermandades suele llevarse además por mujeres de determinadas familias que con paso del tiempo son sucedidas por otras del mismo entorno. Petra Moya comenta ilustrativamente sobre esto:

Yo soy muy crucera de la Fuente. Es por ascendencia que he traído de mi abuela, de mi bisabuela, porque mi madre y mi padre me contaban de toda la gente mayor de ellos, son de aquí, de la calle la Fuente, porque por lo visto es la primera Cruz que se hizo en Almonaster. Esa trascendencia de atrás la traigo, pero bien sabe Dios que yo no me enfado con nadie a tento de cruces, porque esto es un pueblo muy chico, nos conocemos todo el mundo y tenemos que estar todo el año conviviendo (Petra Moya, encargada de la Cruz de la Fuente, entrevista personal, feb. 2007). 


\section{COPLAS DEL ROMERO. VOZ E IMAGEN DE MUJER EN UN CANTO PROCESIONAL}

Por la mañana del Domingo de la Cruz, las jóvenes cruceras $^{13}$ se engalanan con elegantes trajes de serrana y mantones de Manila para el ritual de la fiesta, comenzando por el Romero o camino en el que se celebra la Cruz. El recorrido se inicia en la propia Cruz; tras recoger a la mayordoma y diputadas, vuelven a su cruz y avanzan hacia una zona del campo cercano donde espera el mayordomo con sus diputados, montado a caballo. Allí la mayordoma le entrega la bandera que traerá, ahora el mayordomo, de regreso al pueblo acompañando al grupo de serranas. Al llegar al casco urbano visitan la otra cruz, después el ayuntamiento y la iglesia donde se realiza otra ofrenda del romero, para terminar en su propia cruz a la que dan simbólicamente tres vueltas colocando finalmente la bandera.

También se denomina Romero al cortejo de serranas que realiza este ritual. Encabezan el grupo las pandereteras, entre ocho y doce cruceras que abren la comitiva

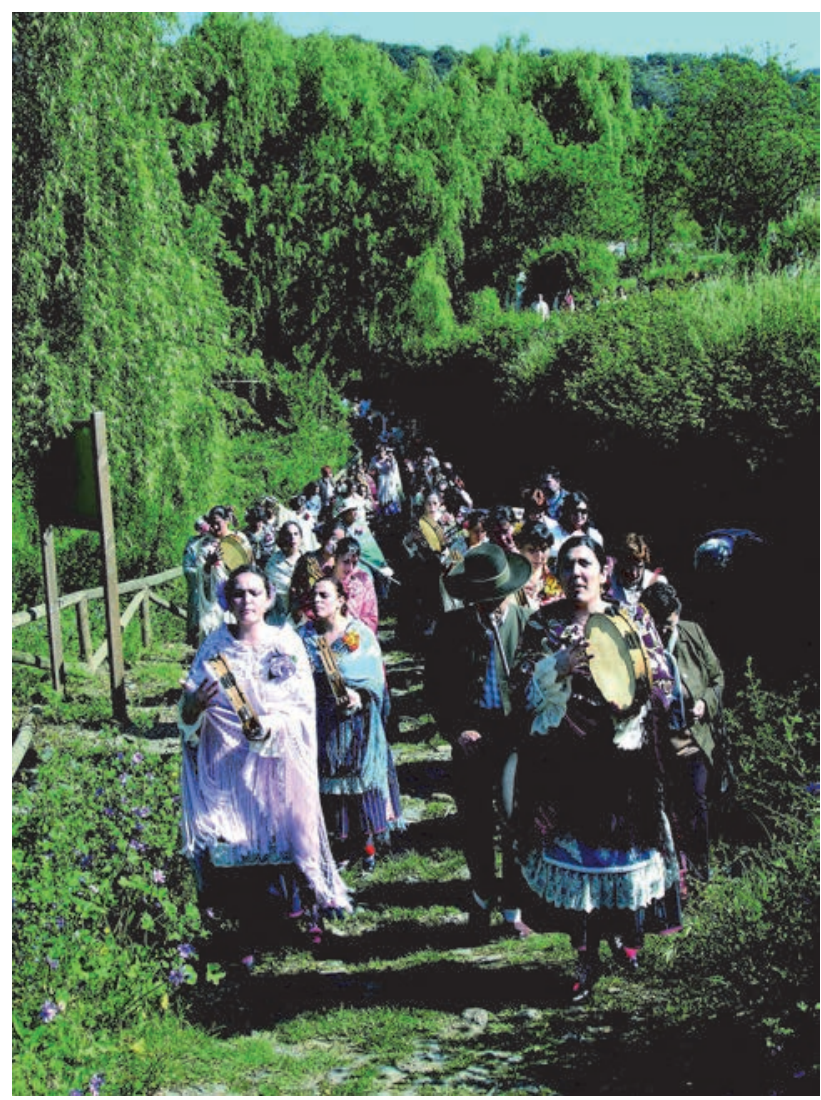

Figura 4.-Cortejo de serranas cantando las coplas del Romero. Cruz de la Fuente. Foto de Herminia Arredondo y Francisco J. García Gallardo

\footnotetext{
${ }^{13}$ Sobre todo jóvenes solteras.
} 
con sus panderetas, junto al tamborilero. A continuación la mayordoma, figura principal de la fiesta, con sus dos diputadas; y siguiéndolas, otro grupo numeroso de serranas. En la procesión, en un contexto muy ceremonial, el cortejo se dispone en dos filas paralelas formando un elegante y armonioso conjunto que avanza a tempo lento, calmado [Figuras 4 y 5 ].

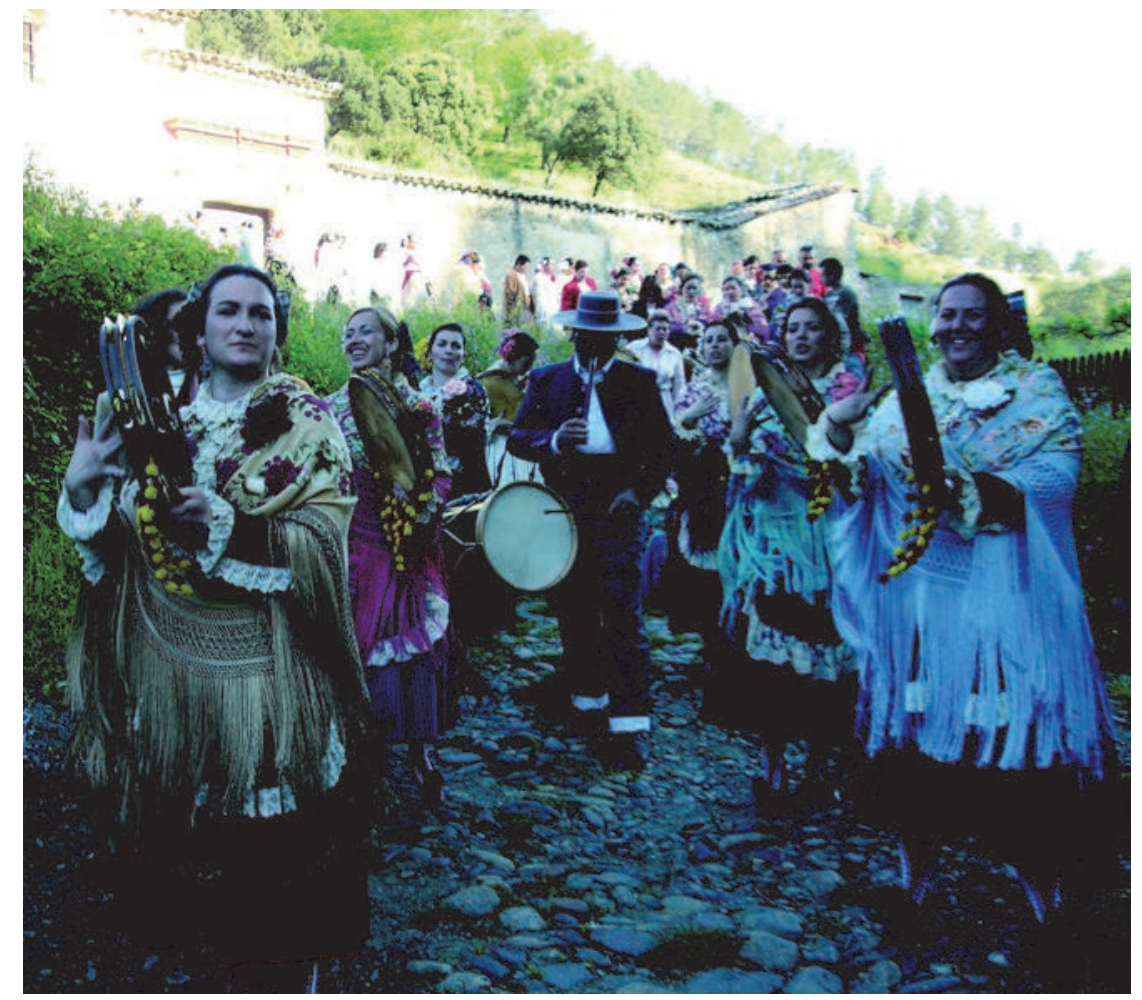

Figura 5.-Cortejo de serranas cantando las coplas del Romero. Cruz del Llano. Foto de Herminia Arredondo y Francisco J. García Gallardo

Como si de un viaje ceremonial simbólico se tratara, la procesión del Romero tiene una duración de varias horas en las que se canta sin interrupción un extenso número de letras denominadas coplas del Romero. Son canciones en verso que las cruceras interpretan siempre con la misma música y acompañamiento del toque de pandereta. Junto a ellas, gaita y tambor aportan una base melódica y rítmica al grupo.

En el conjunto estético de la fiesta, la música de estas coplas, así como de los fandangos, no solo proporciona aún más embellecimiento y esplendor al ritual festivo, sino que con su capacidad de conducir y crear intensos estados emocionales intensifica las experiencias de los asistentes creando auténticos "sentidos de lugar" en la concepción de Feld y Basso (1996: 11) cuando se refieren a "los modos expresivos y experienciales en que los lugares son conocidos, imaginados, añorados, considerados, recordados, expresados, vividos, contestados y luchados; las múltiples formas en 
que los lugares están metonímica y metafóricamente ligados a la identidad". No cabe duda, que la performance de la fiesta y la música participan en la creación de esos sentidos en este contexto festivo de Almonaster como veremos.

Las coplas del Romero ${ }^{14}$, si fundamentalmente son de temática religiosa - la devoción a la Cruz y Jesucristo-, otras tienen que ver con los actos del ritual. Con «un sentido didáctico" (Manuel Ángel Barroso, entrevista personal, ene. 2007), narran la relación de Jesús con la cruz o describen y puntúan las distintas fases y eventos del rito en Almonaster. Aluden así a diferentes momentos de la historia sagrada: la crucifixión, la Pasión, la venida de Jesús para redimir al pueblo, la madre que siempre lo acompaña..., y sobre todo, la adoración a la cruz como símbolo religioso. Entre estas:

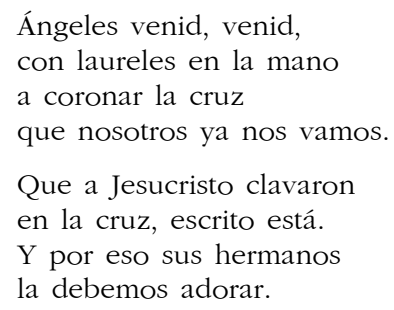

Además de esta temática, cada paisaje, elemento o símbolo del entorno natural y urbano considerado significativo, así como cada momento especial y la secuencia de eventos del largo ritual, son descritos o apuntados en las coplas. Estas referencias emblemáticas participan en la construcción de la especial vivencia del lugar con fuerte sentido de identidad para los participantes. A modo de ejemplo, ya que el repertorio es muy amplio, mostramos solo algunas en las que alude a estos.

En la casa de la mayordoma:

Dónde está la mayordoma,

la de la calle la Fuente.

Dios le dé mucha salud

para que lo sea siempre.

Entrega de la bandera (mayordoma a mayordomo) [Figura 6]:

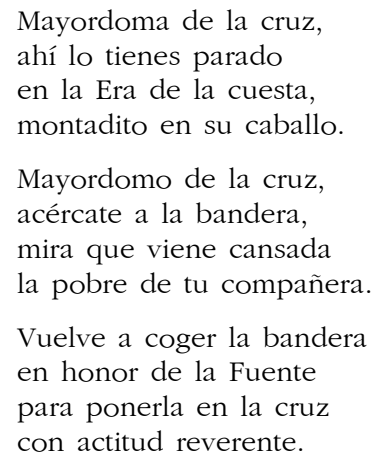

\footnotetext{
${ }^{14}$ Todas las coplas citadas en este texto fueron recogidas en el trabajo de campo que realizamos en Almonaster la Real durante las Cruces de 2006, 2007 y 2012.
} 


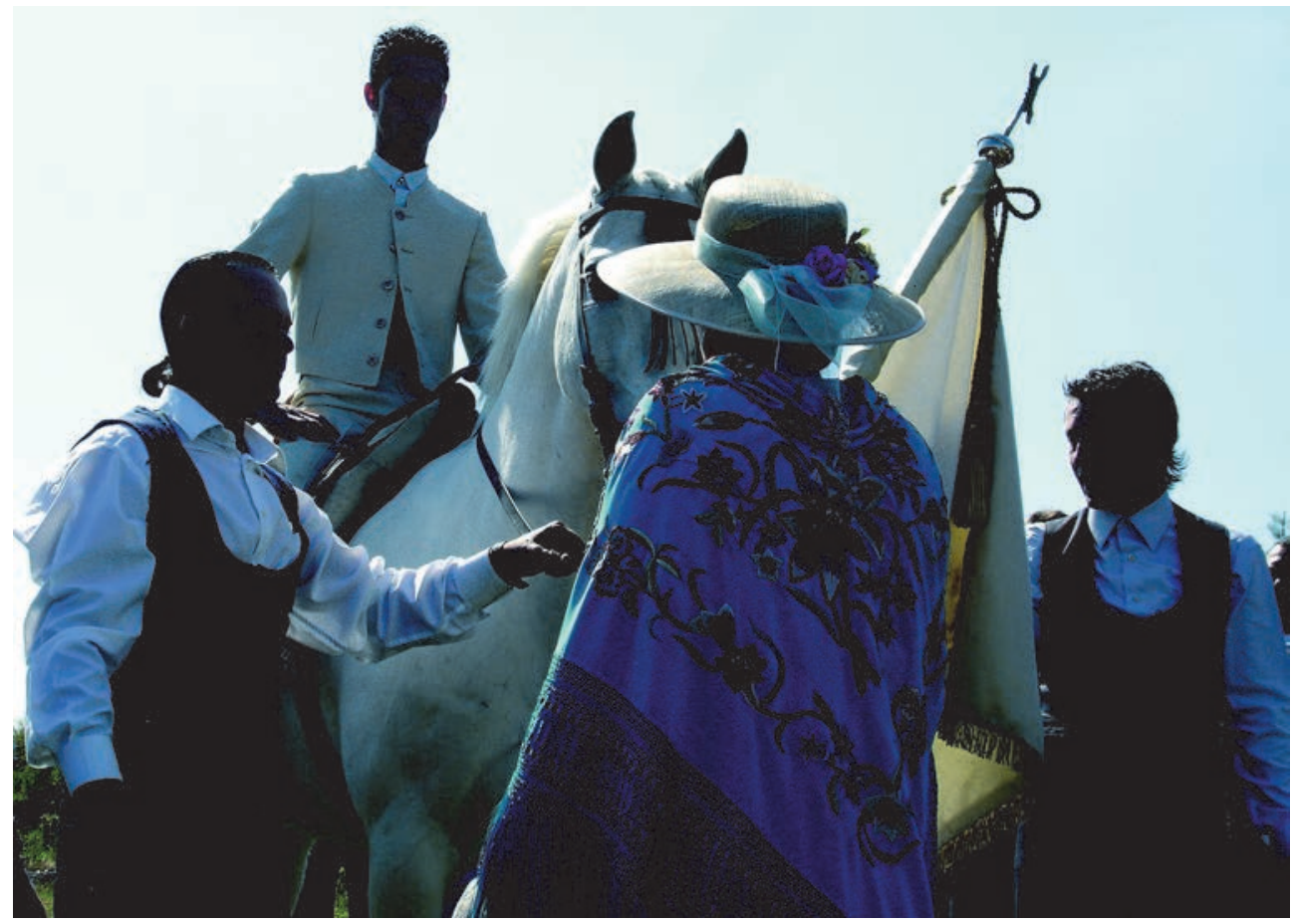

FIgURA 6.-Mayordoma entrega la bandera al mayordomo en la Era de la cuesta. Foto de Herminia Arredondo y Francisco J. García Gallardo

Ofrenda en la iglesia:

Acércate mayordoma [del Llano]

con el romero a la cruz,

que en ella crucificaron

a nuestro Padre Jesús.

Las serranas de la Fuente

están todas muy contentas.

para ofrecer el romero

en la Santa Iglesia entran.

Llegada a la cruz. Tres vueltas con el romero en la mano [Figura 7]:

Vamos llegando a la cruz,

hagamos la reverencia,

que en ella murió Jesús

cuando inclinó la cabeza.

Qué bonita está la cruz

por la mañana temprano

cuando llegan las serranas

con el romero en la mano. 


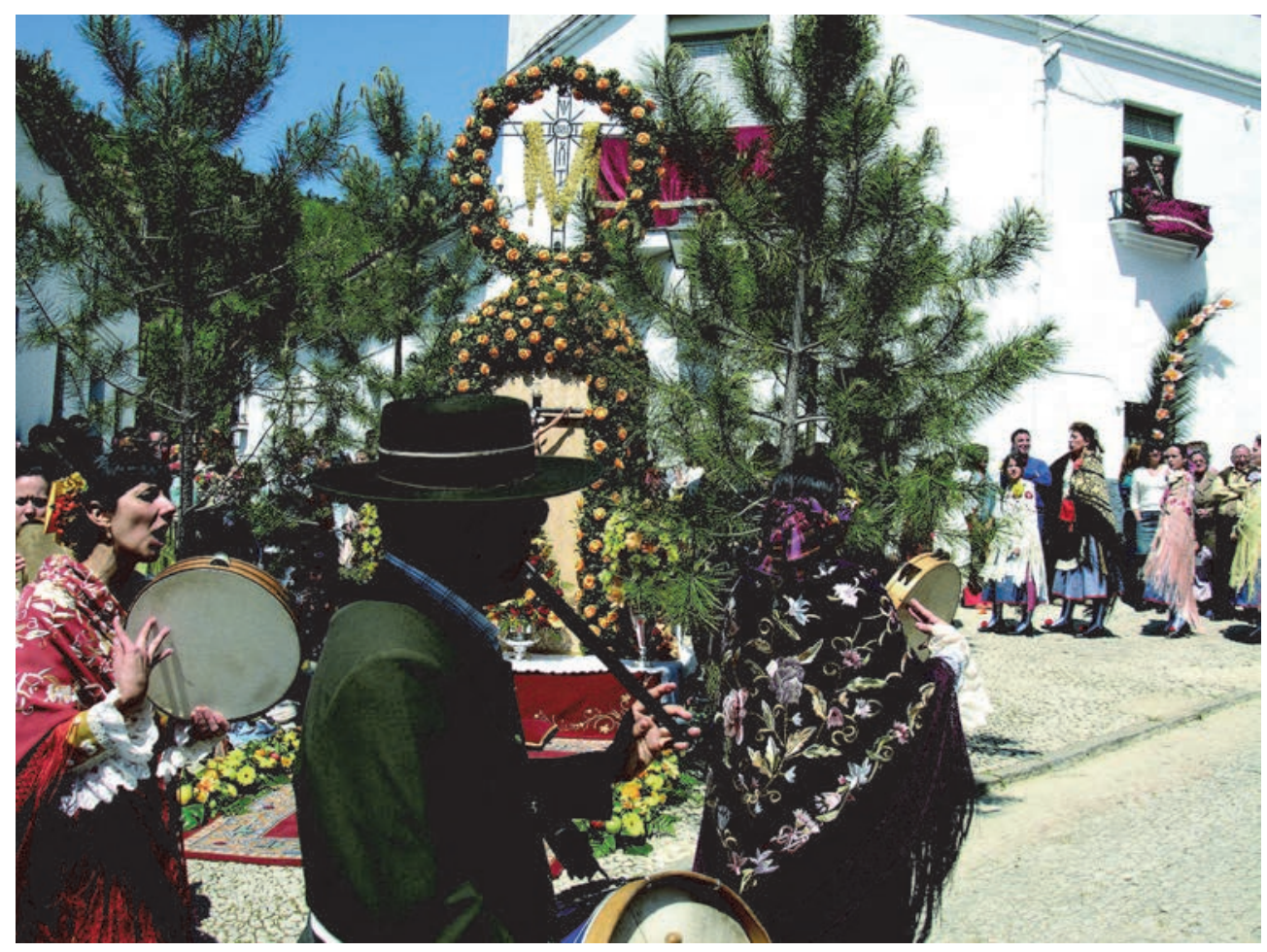

Figura 7.- Vuelta a la Cruz en la Fuente. Foto de Herminia Arredondo y Francisco J. García Gallardo

Las coplas del Romero, en la voz femenina del cortejo de serranas con el sonido incesante de las panderetas, acompañan todos los actos como expresión de un canto o rezo procesional que llega a embelesar. El contenido de los textos, que claramente ha tenido una función educativa y moral en otra época en esta sociedad, pone de relieve la vinculación tradicional de la mujer con actitudes de adoración a la cruz como símbolo religioso y como elemento protector de la vida. Estas coplas representan una visión de la religiosidad de protagonismo femenino donde el papel de la mujer es el de guardiana espiritual de este tipo de ideas, de mediadora con el mundo sagrado, asistente en los ritos de paso, y encargada de la adoración y cuidado de la cruz sea por creencia religiosa, pseudomágico-religiosa, o por convicción en el valor cultural local de esta manifestación. También exponen el vínculo del sexo femenino con la naturaleza, la vida y la fertilidad, subrayado por valores ideológicos y roles sexuales de la sociedad rural tradicional: la mujer como procreadora y protectora de la vida, de la pareja hombre-mujer, de la virtud y pureza sexual.

Pero no solo el mensaje que se transmite a través del texto, sino la interpretación musical en la voz femenina, la propia imagen corporal y el desarrollo del ritual por las cruceras enfatizan estos valores de la sociedad rural tradicional relacionados con el género y con una definición patriarcal de la feminidad. Las mujeres cruceras conducen el camino espiritual del cortejo ceremonial con sus coplas a través de una 
melodía vocal y el toque instrumental continuo e iterativo, como una plegaria. En muestra de devoción o respeto, al final del recorrido realizan actos de ofrenda y reverencia a la cruz con gran simbología; y a la comunidad, cuando por ejemplo la mayordoma saluda protocolariamente a la autoridad municipal. Con su conducta e imagen corporal durante los actos del ritual, su actitud de decoro, y su mismo vestuario del traje tradicional de serrana, elegante y serio, transmiten una imagen de pureza y virtud. Asimismo escenifican el valor de la juventud y de la renovación de la vida en la joven pareja de mayordoma y mayordomo, en los elementos vegetales que rodean todo el espacio y en su propia figura. En este ritual de mayo la mujer crucera encarna la naturaleza y la belleza en sí misma, simbolizada en la flor que adorna su pecho y su pelo. Todo ello lo expresa además, públicamente, con su canto.

Desde luego, la puesta en escena del ritual y la interpretación musical en la Cruz de Almonaster constituye el escenario privilegiado donde interactúan, se mantienen o transforman modelos y valores de género en esta sociedad. La interpretación del Romero en la fiesta de la Cruz viene a afirmar modelos e ideas sobre la mujer que se han conformado en la sociedad rural tradicional y ello, de acuerdo a valores ideológicos religiosos y morales sobre los sexos.

\section{FANDANGOS DE LA CRUZ. COHESIÓN E IDENTIDAD EN LA INTERPRETACIÓN MUSICAL FEMENINA}

A lo largo de los actos previos y en los días de celebración, también se cantan un amplio grupo de fandangos: los de cada una de las cruces, el fandango de la Jira o salida al campo, y el de la Noche de los Pinos. Además de estos estilos, durante la celebración de su romería se cantan y bailan los fandangos de Santa Eulalia. Y para completar este rico patrimonio, Almonaster también cuenta con los fandangos aldeanos, recogidos en las aldeas de La Escalada y Calabazares.

Los fandangos de la Cruz o de las Cruces, designados así de forma genérica, constituyen un tipo o estilo común formado por todos aquellos que se cantan en cada una de las dos cruces del pueblo al finalizar el ritual del Romero (el fandango de la Fuente y el del Llano), los que se cantan en la Cruz de la aldea de Aguafría y los de la Cruz del Hoyo o fandangos repicaos en la aldea de Las Veredas ${ }^{15}$.

Los fandangos de los Pinos y de la Jira son estilos algo diferentes. El de los Pinos se interpreta esa noche, cuando las dos hermandades rondan las calles del pueblo dirigiéndose coplas de pique. El de la Jira, cantado específicamente por la Fuente el martes siguiente a la Cruz, solo se diferencia por su forma de interpretación más viva, ya en el final de la fiesta.

Todos estos fandangos, de las Cruces, de los Pinos y la Jira, tienen la estructura habitual de la forma fandango en Huelva: una introducción o estribillo instrumental seguida de la copla cantada que consta de seis frases con una estructura literaria y unos parámetros musicales característicos ${ }^{16}$. Cada estrofa, temáticamente independiente,

\footnotetext{
${ }^{15}$ Desde el año 2014 también la aldea de Calabazares ha comenzado a celebrar la Cruz de Mayo.

${ }^{16}$ Sobre fandangos de Andalucía y transcripciones musicales de algunos de ellos, puede verse el trabajo de Miguel Ángel Berlanga (2000) Bailes de candil andaluces y Fiesta de verdiales. Otra visión de los fandangos.
} 
es una unidad o composición poética individual aunque a veces se puedan cantar seguidas varias coplas con una temática parecida. Desde el punto de vista de las características musicales, cada uno de los estilos presenta sus propias peculiaridades y una sucesión melódica particular.

En la celebración de la Cruz de Mayo tanto en Almonaster como en sus aldeas, los fandangos han quedado vinculados a la interpretación vocal y creatividad femenina. Aunque algunos hombres del pueblo se suman en ocasiones, su representación no es relevante. La interpretación tiene lugar por los dos grupos de cruceras en los cuatro días de celebración de la fiesta y en los actos preliminares de la semana anterior. Uno de ellos, el más importante, tiene lugar el Domingo de la Cruz al finalizar el Romero, por la mañana en la Fuente y por la tarde en el Llano. Otras ocasiones son el Domingo de chubarba y la Tarde de las Flores al presentar a la nueva mayordoma.

En el Día de la Cruz, después del Romero, las serranas cantan los fandangos con gran entusiasmo, reunidas en un amplio corro junto a su cruz. En esta manifestación colectiva, a las cruceras como protagonistas de la fiesta también se pueden sumar otras mujeres y hombres del pueblo que allí se congreguen. Una de las pandereteras, a la que se asigna esta tarea por su experiencia y buena interpretación, se encarga de iniciar las primeras palabras del texto del fandango, seleccionando la letra, y a continuación le sigue el resto. La única figura individual que encontramos en la interpretación instrumental del conjunto es la del tamborilero. Con el toque de las panderetas y el acompañamiento de la gaita y el tamboril, las serranas cantan un gran número de coplas de fandangos cuya música resulta más llamativa y animada que la del Romero.

Este momento de reunión y cante tiene una gran carga simbólica e identitaria para los vecinos de Almonaster. Es el culmen de la fiesta, la celebración y exaltación final de la Cruz en todos sus sentidos. La Cruz viene a aglutinar en ese acto muchos de los significados que tiene para el grupo de mujeres identificadas fuertemente con ella, y para los demás hombres y mujeres vinculados a esta manifestación cultural. Significados que tienen que ver con la cruz como símbolo religioso, objeto de devoción y exaltación, o como referente simbólico que une armónicamente al grupo de personas que se identifica con una tradición local en una manifestación colectiva de júbilo, como espacio o marco simbólico en el que mujer y hombre expresan de una forma especial sentimientos de amor que van quedando recogidos y codificados en las letras de los fandangos, y asimismo como un intenso momento de placer y gozo que crea a través de la música un especial "sentido del lugar" (Feld y Basso 1996: 3-13) de fuerte identidad (Stokes 1994: 5) e intensidad. Espacio y lugar intensificado en el que "la práctica musical sitúa la memoria y la interpretación proporciona el sentido del lugar" (Bohlman 2003: 334), potenciado por la "sensitividad" del exultante ambiente primaveral y la agitación interior que crea el mes del amor por excelencia.

Las letras de los fandangos ${ }^{17}$ ensalzan a la cruz y a las personas vinculadas a ella, expresan sentimientos sobre el amor y la fiesta fundamentalmente. Unos celebran la fiesta, el vínculo colectivo de los llaneros o callefuenteros y la unión emocional a los hermanos cruceros y cruceras:

${ }^{17}$ Los fandangos citados en este texto fueron recogidos en el trabajo de campo que realizamos en Almonaster la Real (2006, 2007 y 2012). 
Hermosa fiesta de mayo.

Almonaster la Real.

Hermosa fiesta de mayo.

¡Viva la Cruz de la Fuente!

¡Vivan todos sus hermanos!

Almonaster la Real.

De Almonaster la Real, es la calle de la Fuente, de Almonaster la Real.

Adoran su cruz bendita

y al Señor de la Piedad.

Es la calle de la Fuente.

San Martín es mi patrón,

¡Viva el Llano! que es mi tierra

y San Martín es mi patrón.

¡Viva el Llano! que es mi tierra,

¡Viva la gente del Llano!

porque de el Llano soy yo.

El cante que aprecio siempre,

el fandango es mi alegría,

el cante que aprecio siempre.

Que quita las penas mías

el fandango de la Fuente.

El fandango es mi alegría.

Otros muchos muestran un contenido poético de profundos sentimientos personales que se expresan y sienten individual y colectivamente a través de letras de amor, alegría o desamor. En ocasiones presentan el amor vinculado a la sensitividad y la simbología primaveral — naturaleza, vegetación, astros... - inserta en este contexto con un sentido metafórico de connotaciones relacionadas con el cuerpo, la fertilidad, o el encuentro amoroso de los amantes (Frenk 1978); así como la juventud, la belleza, la pasión, el canto como alegría, consuelo o alivio, etc., imágenes también habituales en canciones de amor de otras tradiciones musicales. En la Cruz del Hoyo de Las Veredas y en Almonaster cantan por ejemplo:

Un fandango le canté,

lo vi llorar sin consuelo,

un fandango le canté.

Por un milagro del cielo

las lágrimas le sequé,

mi fandango fue el pañuelo.

¿Dónde estuviste ayer,

hermoso lirio del valle?

¿Dónde estuviste ayer,

que mis ojos te buscaron

y no te pudieron ver,

hermoso lirio del valle? 
Por la verea del cielo, la luna va caminando por la verea del cielo, de cuando en cuando se para por ver el color de tu pelo y los ojos de tu cara.

La interpretación musical de estos fandangos en el transcurso de las Cruces de Almonaster pone en juego unas formas expresivas propias y unas peculiaridades que no tienen lugar en otros contextos y situaciones. Aquí la interpretación está vinculada a la mujer, y la forma de cantarse es colectivamente, en grupo, sin responder al modelo de cantaor individual habitual en otros contextos ni a la interpretación virtuosa del profesional, sino a una estética más directa, sencilla, sin demasiado efectismo. Al comenzar a cantar, junto a la cruz, las mujeres forman un amplio círculo que rodea al tamborilero y así permanecen durante el espacio de tiempo en el que los interpretan. Con su canto expresan el poder de la mujer en la exposición pública de su voz y afirman una tradición femenina de canto que le otorga gran valor a la colaboración, cohesión e identidad grupal, reforzada visual y auditivamente en el corro.

Asimismo, la parte vocal de los fandangos, una única línea melódica, es cantada por todo el grupo de mujeres de cada cruz con gran homogeneidad. No se trata de un cante individual donde el intérprete recrea personalmente determinados parámetros musicales, sino de una forma de cantar en la que podemos apreciar el empaste y conjunción de las voces de las mujeres en la interpretación del diseño melódico de las frases musicales y la simultaneidad rítmica. Sin necesidad de cualidades vocales excepcionales, el grupo de callefuenteras y llaneras trabaja ese aspecto expresivo relevante, la conjunción y máxima igualdad sonora en el canto. Las mujeres de cada grupo se habitúan a cantar juntas, guiadas por las otras mujeres de su misma cruz. Desde niñas van aprendiendo el amplio repertorio de coplas en las reuniones de las tardes de las Flores, en la celebración de las Cruces y en el Romero infantil. Antiguamente era habitual que ese aprendizaje se llevara a cabo sobre todo en el entorno familiar o de vecindad, pero ahora se suele abordar principalmente en las reuniones en el salón de la hermandad en las Flores. No se trata de ensayos formales, sino de un espacio de tiempo en el que las mujeres van recordando las canciones a la vez que realizan otros preparativos manuales de la fiesta. En determinados momentos, sí se aborda expresamente el aprendizaje de la música, las coplas y/o el toque de la pandereta. Ángeles Ventura, una muchacha joven e intérprete destacada de la Cruz de la Fuente así nos comentaba su forma de aprendizaje (Ángeles Ventura, entrevista personal, abr. 2007):

Yo toco la pandereta desde pequeñita. Ahora una chica, Mercedes y yo, somos las encargadas de enseñarla a las niñas a partir de las siete de la tarde en el mes de las flores. Ellas tienen un Romero también, y tienen que saber tocar la pandereta y las canciones igual que las mayores. Ahí están todas las niñas que desde pequeñitas van aprendiendo. Hay niñas que no les gusta y lo dejan. Las que siguen, suelen seguir de mayores. Cuando ya son mayorcitas pasan al grupo de mayores.

Entre las que sabemos, normalmente casi todos los años, en abril, ya sabemos las que cantan, las que cogemos la pandereta..., se va renovando. Siempre nosotras mismas nos vamos escogiendo, te ofreces..., no hay problema. 
Desde pequeñita te enseñan, pero yo ni siquiera fui a esas clases, yo aprendí de lo que veía, de lo que sabe la gente. Desde pequeñita bailaba y escuchaba la música y cantaba. Siempre he cantado en el colegio, en la casa, en la calle, a mi abuela, a mi vecina..., no me daba vergüenza. [...] Lo que he aprendido es de escucharlo, de escuchárselo a mi abuela, a mis vecinas que son de aquí, de persona a persona... Y como veían que tocaba bien y cantaba, siempre me han dejado abrir el camino del Romero [Figura 8].

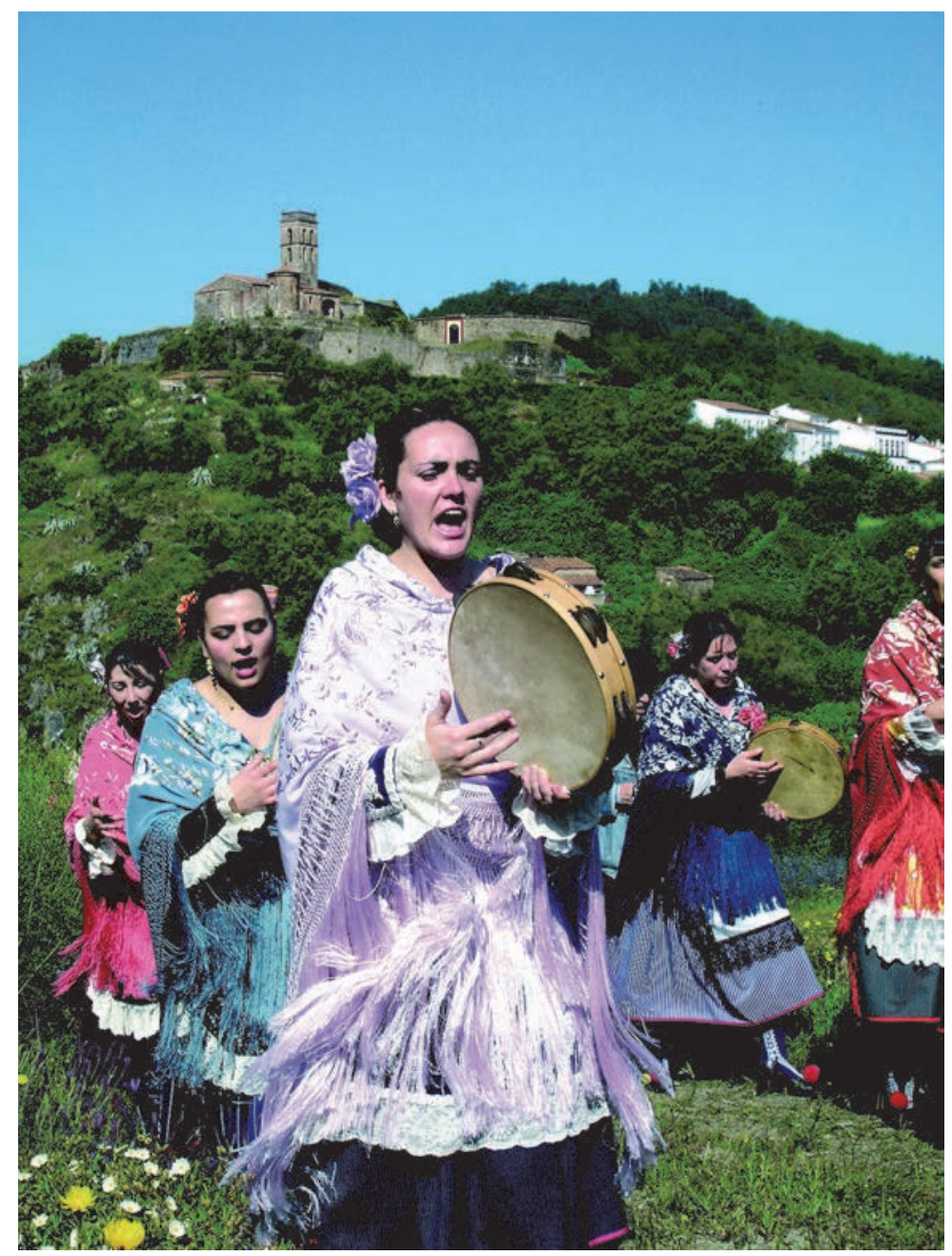

FiguRA 8.- Ángeles Ventura, panderetera abriendo el camino del Romero. Foto de Herminia Arredondo y Francisco J. García Gallardo

Normalmente las niñas aprenden de otras mujeres que les enseñan. Después tienen la oportunidad de escuchar en vivo las canciones en los actos del Día grande de la Cruz, y a continuación vivir la suya propia el lunes de Cruces con el Romero infantil, momento en el que pueden poner en práctica lo que han aprendido. 
La cohesión y uniformidad del sonido en el grupo cuando interpretan el diseño melódico-rítmico de la copla del fandango, puede asimismo observarse en otros parámetros y aspectos expresivos más sutiles y difíciles de lograr colectivamente en la voz, así como en cuestiones musicales de detalle. A través del trabajo de campo, escucha atenta de la interpretación de esta música en el contexto de las Cruces, transcripción y análisis musical, hemos podido estudiar la forma de interpretación específica de estos fandangos y la de cada grupo de cruceras. Por ejemplo, esa uniformidad vocal se observa también en la cualidad sónica de la voz al intentar mantener un sonido y expresividad característica de los estilos locales en este contexto, en la forma de buscar un equilibrio tímbrico entre las distintas voces de las mujeres, al mantener una cualidad de la intensidad sonora, fuerte, pero donde no sobresalga demasiado ninguna voz sobre las demás, así como manteniendo una tesitura común, habitual y característica en el canto en cada grupo de cruceras, que acompañada por el toque de la gaita, ha venido variando muy poco en un amplio espacio de tiempo.

Esta forma de expresar los fandangos de cada una de las cruces, mantenida en la práctica oral, se aprecia asimismo en algunos aspectos musicales en más detalle como en la ornamentación que cada grupo introduce en la melodía vocal, en la articulación y en el uso de portamentos y glissandi en la conducción de la voz ejecutados de manera muy uniforme entre las mujeres que cantan. Desde luego, la interpretación rítmica de las frases musicales, en la que mantienen una regularidad bastante estricta del compás, sin rubato, ayuda a proporcionar simultaneidad y conjunción auditiva al canto. Del mismo modo, el sonido de las panderetas es bastante análogo en cada grupo de intérpretes cruceras. Normalmente todas las panderetas que se tocan en los actos oficiales son muy similares en tamaño y características; a esta igualdad se une la técnica de toque, con un movimiento y gesto de la mano que se trabaja para que llegue a ser lo más afín posible en todas las pandereteras tras años de aprendizaje y práctica.

Sin duda, la interpretación de los fandangos de la Cruz en cada grupo de cruceras, tan compenetrado auditiva, corporal y visualmente, refuerza el sentido de unidad e identidad del grupo de mujeres y de identidad local de las cruces. Cantar juntos los fandangos con la alegría del final de la fiesta resulta una viva manifestación de celebración colectiva del grupo, de la Cruz, y de Almonaster. Las mujeres dan voz a esta práctica, simbolizan la tradición y "orquestan la experiencia colectiva" (Tolbert 1994: 180) de alegría y de hermandad.

EL FANDANGO DE LOS PINOS Y EL PIQUE: LA MÚSICA COMO ARTICULADORA DE LA DIFERENCIA

Otro estilo de fandango, el de los Pinos, se interpreta en uno de los momentos de más intensidad de la fiesta de las Cruces en Almonaster, la Noche de los Pinos en la madrugada del sábado al Domingo de la Cruz. Su denominación está relacionada con los pinos que los hombres cortan en el campo y trasladan al pueblo para colocarlos simbólicamente a los lados de la Cruz en una demostración de su fuerza masculina ${ }^{18}$.

\footnotetext{
${ }^{18}$ Actualmente se cortan con anterioridad a ese día pero se mantiene la fiesta.
} 
Constituye uno de los momentos más llamativos de la fiesta cuando, entre salvas de cohetes, las dos hermandades rondan las calles del pueblo cantando estos fandangos, algunos de ellos con letras de pique, en un ambiente de intensa carga emotiva. A media noche, cada hermandad sale desde su cruz para dirigirse hacia la otra. Siguiendo unas reglas establecidas, primero la Fuente se dirige hacia el Llano y después al contrario. Cuando se acercan y pasan por delante de la otra cruz, la fiesta alcanza el momento álgido en el que se potencia la pugna y se agudiza el pique. Durante esos minutos, los fandangos se cantan con más osadía y más potencia sonora para imponerse a los otros así como al fondo ruidoso de salvas y gritos de exaltación a la Cruz y a los hermanos [Figura 9]. Las pandereteras tocan más fuerte y el tamborilero también tiene que hacer un gran esfuerzo para que se le escuche. El clima sonoro y verbal se vuelve más intenso.

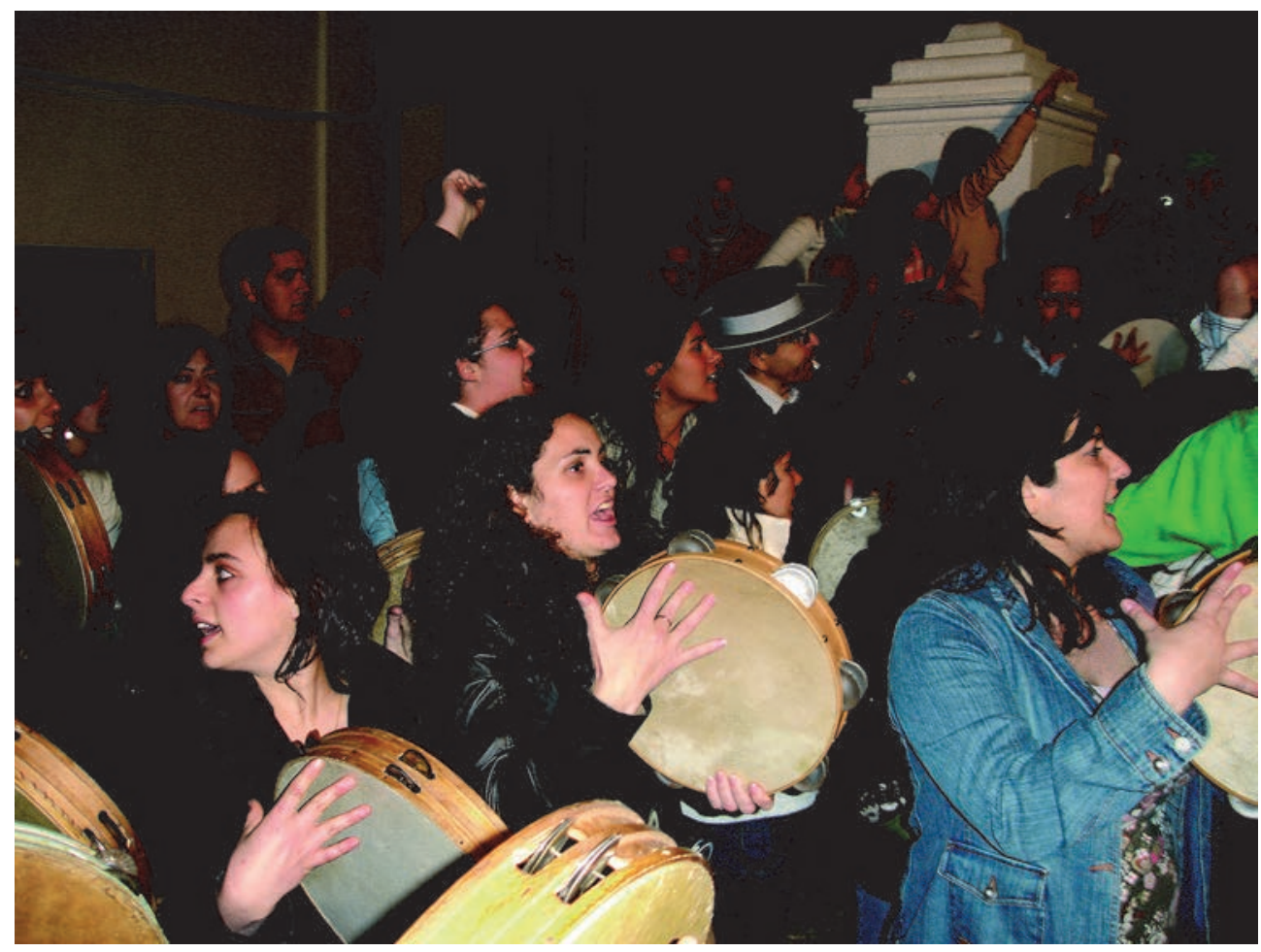

Figura 9.-Cantando fandangos de pique en la Noche de los Pinos.

Foto de Herminia Arredondo y Francisco J. García Gallardo

La competición es consustancial a la celebración de las Cruces de Mayo en muchas localidades de Huelva donde habitualmente encontramos más de una cruz con un bando, barrio o grupo de personas vinculado a ella. Todas tienen el propósito de enfatizar al máximo la suya e intentar superar a las demás en lujo decorativo, objetos simbólicos, vestuario, puesta en escena y celebración (Campo y Corpas 2005; Jiménez 2004 y 2011; Rodríguez 2004), y de forma especialmente expresiva, en música y poe- 
sía. En Almonaster la rivalidad entre ambos barrios es ordenada socialmente en el ritual público y canalizada expresivamente a través de las coplas de pique entre llaneros y callefuenteros $^{19}$. Pero si en otras localidades el debate y el pique dialéctico recitado o cantado es manifestado de forma mayoritaria por el género masculino, o en todo caso conjuntamente por el grupo de hombres y mujeres de cada bando, en Almonaster resulta llamativo que esta práctica sea asumida exclusivamente por las mujeres en el contexto de esta fiesta. El protagonismo femenino en esta celebración festiva y en el desarrollo del ritual ha contribuido a que la mujer exprese públicamente su canto, tanto canciones que van manteniendo en la tradición oral como nuevas letras, inventadas cada año, desarrollando así una actividad creativa históricamente vinculada a los hombres en otros contextos.

El repertorio poético de los fandangos de los Pinos incluye un amplio número de textos, no solo de pique. Algunas letras, tanto nuevas como las habituales de todos los años, son exclusivas de esa noche, no se cantan en otra ocasión. Unas nos hablan de la ancestral tradición de cortar y plantar los pinos, aunque sin apenas connotaciones eróticas masculinas del árbol mayo. Seguramente ha habido más textos de los que se conservan, pero entre los que todavía se cantan y expresan cierta relación con los pinos se encuentran, por ejemplo ${ }^{20}$ :
Atravesando pinares, toda la noche me llevo atravesando pinares, para darle los buenos días al divino sol que sale, toda la noche me llevo.
Quien tiene piñas, piñones, alto pino tiene piñas, quien tiene piñas, piñones. Quien tiene amor, tiene celos, quien tiene celos, pasiones. Alto pino tiene piñas.
Por ver si la divisaba, al alto pino subí por ver si la divisaba. Lo que divisé fue el polvo del coche que la llevaba. Al alto pino subí.

Otras se dedican, por ejemplo, a ensalzar la propia cruz, a los hermanos cruceros, llaneros y callefuenteros, "sin echar por tierra a la otra cruz, pero sí poniendo la nuestra en lo más alto, en los altares" como nos explica literalmente una crucera (Ángeles Ventura, entrevista personal, feb. 2007). También, al amor, creencias religiosas, emociones personales...

\footnotetext{
${ }^{19}$ El cante de coplas de pique y coplas satíricas está documentado en archivos de la provincia de Huelva al menos desde el siglo XVIII (Canterla 2012 y 2014).

${ }^{20}$ Fandangos recogidos en el trabajo de campo realizado en Almonaster la Real (may. 2006, 2007 y 2012).
} 
El cante que llega al cielo, el fandango es mi alegría. El cante que llega al cielo, que quita las penas mías, un fandanguillo llanero. El fandango es mi alegría.

Todo el que pasa se queda, ¿Qué es lo que tiene la Fuente que todo el que pasa se queda?

Eso dijo uno del Llano.

¡Vivan las callefuenteras, vivan todos sus hermanos!

Ahora y siempre lo diré: ¡Viva el Llano, viva el Llano! Ahora y siempre lo diré. Donde quiera que me vaya del Llano me acordaré ¡Viva el Llano, viva el Llano!

$\mathrm{Y}$ un grupo representativo viene constituido por los fandangos propiamente de $p i$ $q u e$, fandangos que se dirigen de una Cruz a otra provocándose. De estos, algunos se cantan habitualmente todos los años, piques clásicos entre las cruces, como por ejemplo la letra que la Fuente canta al Llano reprobándole que no es la cruz original. Para Aguilera (1995: 77) esta diferencia de las cruces, aunque matizada, ha estado además vinculada históricamente a los grupos sociales predominantes en el pueblo, a sectores de la población con distinto nivel socioeconómico, la hermandad del Llano con la clase más acomodada, y la Cruz de la Fuente con vecinos menos pudientes. Por eso se canta el fandango Tres caballos y mucha gente, como nos dice Manuel Ángel Barroso: "porque el Llano lleva tres y la Fuente solo uno, y eso no es otra cosa que símbolo de la riqueza” (Manuel Ángel Barroso Trujillo, entrevista personal, ene. 2006).

Tres caballos y mucha gente.

Qué importa que el Llano tenga

tres caballos y mucha gente,

si el Llano siempre será

una copia de la Fuente.

O al contrario:
También con mucha gente.
Es mejor con tres caballos
y también con mucha gente para ganar en las Cruces a la calle de la Fuente.

Tampoco falta en el pique el aspecto creativo, ya que siempre tiene que haber novedad, improvisación y algún aspecto diferenciador entre cada grupo en el desarrollo de la fiesta. Junto a letras reiterativas, otras son nuevas, compuestas expresamente para dirigirlas a protagonistas, familiares y allegados de ese año en cada cruz, "en las que los más malparados suelen ser los representantes de ambas hermanda- 
des" (Barroso 1996: 26). Las cruceras aprovechan cualquier suceso o anécdota relacionada principalmente con los encargados de la otra cruz, o algún acontecimiento llamativo que haya ocurrido en el pueblo para registrarlo en la letra de un fandango. En el mes de Las Flores o poco antes de la Cruz, algunas mujeres componen y seleccionan nuevas letras para cantar, aproximadamente unas diez, quince o veinte letras. Se trata de textos efímeros que se suelen interpretar solo esa noche y en alguna ocasión se mantienen algunos días más. Su contenido suele ser gracioso, sobre algo llamativo o exagerado que caracterice a la otra persona, pero sin excesiva mofa ni crítica ofensiva. Coplas en las que se ataca musicalmente a la parte contraria, a los protagonistas de la fiesta principalmente con sentido lúdico.

Si la competitividad por superar al otro grupo o hermandad es intrínseca a las Cruces de Almonaster, en muchos elementos de la fiesta y de la puesta en escena del ritual, la música canaliza y expone de manera más llamativa, pero también más profunda, esa separación dual en los fandangos de las Cruces y expresamente en estos fandangos de los Pinos a través del pique sonoro. Más aún, la música articula la diferencia entre los dos grupos de mujeres o cruces. Aunque ambos canten el mismo fandango - la variante o estilo de los Pinos-, cada uno aporta su propia singularidad definiendo su diferencia de forma expresa. Además de las letras que de manera evidente difieren en cada cruz, incluso las que no se componen nuevas para la pugna o pique, la música articula unas cualidades sonoras identificativas de cada una de ellas.

Cada grupo de cruceras ha construido una forma expresiva propia en su música que intenta mantener alterándola lo menos posible y que transmite con la práctica oral imitativa a las nuevas cruceras. Las dos cruces despliegan unos matices distintivos en la forma de cantar, en la intensidad y timbre en la voz, en algunas pequeñas variaciones rítmicas y melódicas en las frases musicales, en el uso de adornos y procedimientos de articulación del sonido entre otros parámetros. En general, la Fuente canta con más intensidad, viveza rítmica y con un timbre de voz más grueso, robusto, mientras que en la Cruz del Llano el conjunto suele presentar una tesitura un poco más aguda de timbre claro, pero con menos intensidad al cantar en la calle. Tradicionalmente en la Cruz de el Llano solo cantaban el ritual del Romero las mozas, las mujeres solteras, por lo que contaban con un gran número de muchachas jóvenes de voz aguda, pero ahora en las dos hermandades las cruceras son igualmente jóvenes y tanto en una como en otra, mujeres de edad adulta pueden unirse para cantar los fandangos, sin que haya mucha diferencia de edad. También, el menor número de serranas que habitualmente ha tenido la Fuente en otra época, al ser un barrio más pequeño, posiblemente haya demandado a las mujeres cantar con más brío para así poder sobresalir especialmente en el pique. Pero junto a estas cuestiones que lógicamente han podido influir, la diferencia no obstante, responde también a decisiones estilísticas y de personalidad en la tradición de canto en cada una de las cruces. Cada grupo ha creado su expresividad musical específica a partir del mismo estilo de fandangos, del mismo cante.

De igual modo, el toque de pandereta mantiene una singularidad sonora en cada uno. Las panderetas son distintas; asimismo, la técnica de toque aporta ciertas diferencias fundamentalmente tímbricas y de textura rítmica en los dos grupos. Incluso la decoración del instrumento con ramas vegetales y otros elementos decorativos es diferente en el Llano y la Fuente. Las mujeres desean presentar sus interpretaciones musicales como reflejo 
de su propia imagen marcando la identidad del grupo y diferencia respecto al otro. Desde la misma estructura musical y estilística general de cada estilo de fandango, cada grupo crea sus formas expresivas propias a través de finos matices musicales.

\section{CONCLUSIONES. ROLES E IDEAS DE GÉNERO EN LA INTERPRETACIÓN Y ELABO- RACIÓN MUSICAL}

La interpretación musical de los fandangos y las coplas del Romero en la Cruz de Mayo constituye un espacio único en el que las mujeres de Almonaster la Real pueden mantener o transformar roles que históricamente han estado ligados a un determinado género.

En las Cruces, las mujeres se ocupan de garantizar la continuidad de la fiesta y la música vinculada a ella. Con mayor o menor participación de serranas y gente del pueblo, y con distinto esplendor ceremonial, la fiesta no ha dejado de celebrarse desde que recuerdan, sin ruptura en el tiempo, reconstrucción y/o descontextualización. El papel de la mujer como conservadora y transmisora de la cultura tradicional local, de numerosas tradiciones musicales, de baile y poesía, común en nuestra sociedad y otras culturas del mundo (Bithell 2003; Cook y Tsou 1994; Herdorn y Ziegler 1990; Koskoff 1987; Magrini 2003; Silverman 1996; Sugarman 1997), aún tiene un peso importante en la localidad. Las mujeres, sobre todo las de más edad, se sienten comprometidas con el valor cultural y social de estas prácticas en su comunidad y con la responsabilidad de transmitir esta herencia a las siguientes generaciones.

Del mismo modo, en la interpretación musical de los fandangos y de las coplas en el ritual del Romero, las cruceras afirman su rol e importancia en el canto. Las mujeres siempre han cantado repertorios específica o habitualmente vinculados a ellas en la forma de vida tradicional — canciones de infancia, romances, canciones de amor, religiosas, canciones relacionadas con algunos ritos de paso, etc.- - y han escuchado y asimilado otras. En general han conocido y conservado la mayoría de las canciones de su comunidad y una amplia muestra de la música tradicional local, pero su práctica y manifestación en público ha variado en diferentes momentos y contextos por diferentes razones históricas, ideológicas, socioculturales o materiales (Herdorn y Ziegler 1990; Koskoff 1987; Magrini 2003; McClary 1991; Solie 1995). En las Cruces de Almonaster la Real, las mujeres cantan en todos los actos del ritual y de la fiesta, protagonizando una manifestación exclusivamente femenina en este contexto. Con su canto contribuyen a proporcionar valor a la cultura e interpretación musical de la mujer en una sociedad donde tradicionalmente el prestigio ha estado centrado en el género masculino y en el ámbito público.

El contexto excepcional de la fiesta — ferias, romerías, festividades locales y especialmente las Cruces de Mayo- ofrece a la mujer un espacio de participación más activo que otras manifestaciones culturales públicas. Las mujeres realizan la mayoría de preparativos para estas ocasiones, y ponen en escena el ritual, cantan y/o bailan en función de la convención creada en cada lugar. En Almonaster, la fiesta de la Cruz ha establecido un ámbito único y excepcional de interpretación musical para ellas. Como hemos comentado, durante los días festivos llegan a cantar un gran número de coplas en el extenso tiempo del Romero y varios estilos de fandangos en distintos momentos, al pie de la cruz, en los actos festivos previos, en la noche del sábado al 
Domingo de la Cruz y en el martes de la Jira. Su actividad viene a enfatizar y a recrear roles tradicionalmente vinculados en la sociedad occidental a cada género, de cooperación y gestión del dominio emocional tradicionalmente asociados al femenino, junto a fuerza, poder, status, individualidad y competitividad masculinos (Herdorn 1990: 12). Las mujeres trabajan en la unión y colaboración en cada cruz o grupo a la vez que en la competividad y pique recreado lúdicamente entre los grupos; afirman su rol y capacidad en el canto con una presencia pública más llamativa que la habitual en otros contextos, expresando de este modo su prestigio y valor social; y además muestran su papel en la creación poética y musical, y sobre todo, en la interpretación de la música como forma también de creación.

El rol dominante del músico instrumentista de género masculino [Figura 10] se mantiene en esta fiesta de las Cruces desde que recuerdan los vecinos de la localidad ${ }^{21}$. En los últimos años algunas mujeres están aprendiendo el toque de este instrumento de acompañamiento tan popular y arraigado en las fiestas y romerías de la comarca, el conjunto de la gaita o flauta de tres agujeros y tamboril ${ }^{22}$. Almonaster cuenta con una muchacha joven que ha aprendido a tocar de otro tamborilero local, aunque habitualmente participe solo como acompañante, no como músico oficial.

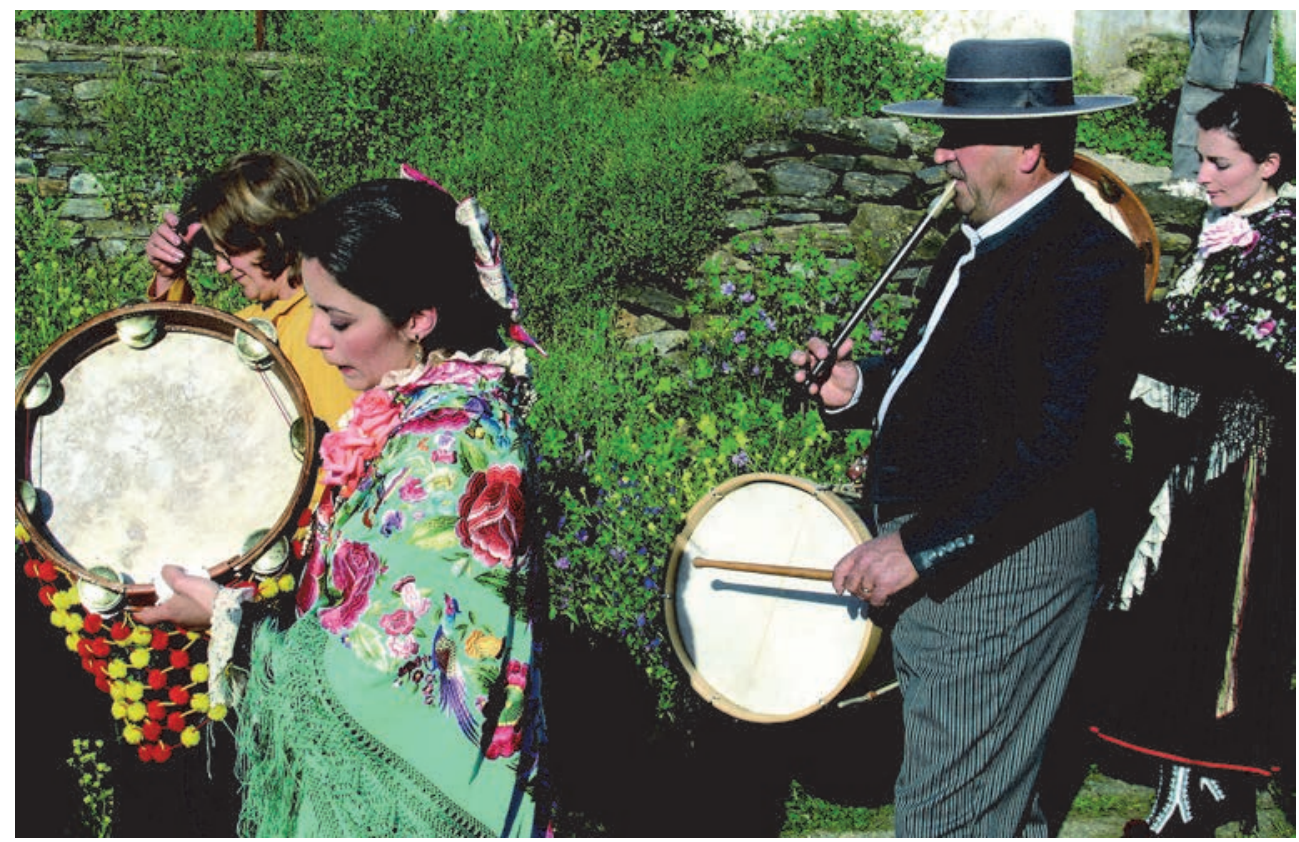

FIgURA 10.- Tamborilero y serranas del Llano. Foto de Herminia Arredondo y Francisco J. García Gallardo

${ }^{21}$ En el trabajo de campo nos han hablado de tamborileros de varias generaciones atrás en el tiempo, oriundos de Almonaster o de sus aldeas, de otras localidades de la provincia, así como de un conocido tamborilero asentado en Sevilla.

${ }^{22}$ Sobre flauta y tamboril en la Sierra y el Andévalo onubenses, ver García y Arredondo (2010 y 2012). 
Flauta y tamboril proporcionan el acompañamiento rítmico y melódico al canto. Junto a estos, las cruceras se acompañan de la pandereta, que como otros instrumentos de percusión ha estado asociada al género femenino en la tradición hispánica y en otras culturas del Mediterráneo (Cohen 1987; Herndon y Ziegler 1990; Magrini 2003; Silverman 2003). Las pandereteras, con bastante práctica y destreza, acompañan los fandangos y las coplas del Romero durante toda la celebración con un toque rítmicamente repetitivo. Entre ocho o doce en cada hermandad, van situadas delante abriendo el cortejo oficial. Otras mujeres pueden participar y tocar con su propia pandereta, no con las de la hermandad, en los demás actos, fuera del Romero oficial.

Sin duda, esta interpretación musical, junto a la performance del ritual, proporciona un contexto privilegiado de expresión pública, negociación y articulación de ideas, valores y sentimientos personales y sociales para las mujeres. A través de la voz y el toque instrumental de las panderetas, con su capacidad vocal interpretativa, su forma expresiva y corporalidad en el canto de cada grupo de cruceras, las mujeres expresan ideas, modelos y sentidos sobre distintos aspectos de su vida: sobre las relaciones de hombres y mujeres, relaciones sociales en la comunidad, relaciones con el entorno, con su forma de vida, con situaciones o elementos emblemáticos de fuerte carga identitaria, aspectos de la espiritualidad y creencia religiosa, emociones personales, etc. Algunos relacionados originalmente con la forma de vida de otra época, pero que al recrearse en el presente en cada nueva performance, contribuyen a reelaborar y crear nuevos significados y a poner en acción vivencias que apelan a sentidos y sentimientos relevantes para los intérpretes y audiencia actual.

En el trabajo etnográfico, de interpretación y análisis en esta investigación, hemos podido observar cómo a través de esta práctica las cruceras y la gente del pueblo vinculada a las dos hermandades canalizan sentimientos colectivos de unión, gusto estético compartido, interés por vivir la emoción festiva con gran placer sensorial, sentido lúdico y ruptura de la cotidianidad, apego a sentir de manera especial el lugar y el tiempo, primaveral, exultante, embellecido para la ocasión. Así también, sentimientos de identidad de género entre las mujeres al compartir la responsabilidad y la experiencia festiva, al cantar en grupo públicamente, al cantar (y a veces crear) un repertorio musical y un universo poético que expresado en su voz proyecta la imagen de identificación con la mujer, al compartir situaciones con fuerte resonancia simbólica para ellas.

Recrean sentimientos colectivos de identidad local que refuerzan el vínculo con la propia tradición cultural y memoria social, así como de identidad grupal al disfrutar de una actividad colectiva, que permite estrechar lazos sociales en el grupo de hermanos y hermanas cruceras, a la vez que sirve para marcar la diferencia, la rivalidad o el pique. Sin olvidar sensaciones individuales que tienen que ver con el propio placer personal de cantar, escuchar y vivenciar sentimientos, con la interpretación musical, la belleza artística de coplas y fandangos, que conmueven a los participantes.

Actualmente, la práctica de cantar y llevar el ceremonial de la Cruz en Almonaster la Real, una actividad predominantemente femenina de gran trascendencia para las mujeres cruceras, también tiene una significación relevante para toda la comunidad, el resto de mujeres y hombres de la localidad. En su mayoría, asisten y participan en el transcurso de la fiesta como oyentes y espectadores, animadores de una de las dos hermandades, como participantes y difusores desde el poder municipal, y en casos 
puntuales como representantes de la hermandad y como representantes oficiales de cada una de las Cruces - mayordomo y diputados elegidos cada año-.

En general, los hombres de Almonaster apoyan los actos festivos, valoran el papel de la mujer en el mantenimiento y elaboración de la tradición local, en la creación poética y en la interpretación musical (Juan Flores, entrevista personal, oct. 2016). Estiman su competencia como intérprete de las coplas y fandangos de la Cruz, y así nos lo comentaron numerosos aficionados locales y del ámbito flamenco.

Aunque se dé esta amplia implicación comunitaria, la mujer crucera sigue siendo protagonista y voz representativa de la Cruz, y mantiene el control de esta expresión. Con la puesta en escena del ritual e interpretación musical la mujer expresa y da forma a su identidad de género y a su propia identidad personal, a ideas, experiencias y sentimientos que forman parte de la realidad de su existencia en el mundo actual.

\section{BIBLIOGRAFÍA CITADA}

Aguilera, Francisco Enrique. 1995. La gente de Santa Eulalia. Almonaster la Real (Huelva). Estructura y proceso ritual en una comunidad andaluza. Huelva: Diputación de Huelva.

Barroso Trujillo, Manuel Ángel. 1996. "El fandango en Almonaster la Real y su contribución a la cultura popular", en X Jornadas del Patrimonio de la Sierra de Huelva: 23-31. Huelva: Diputación Provincial de Huelva.

Berlanga Fernández, Miguel Ángel. 2000. Bailes de candil andaluces y Fiesta de verdiales. Otra visión de los fandangos. Málaga: Diputación de Málaga.

Bithell, Caroline. 2003. "A Man's Game? Engendered Song and the Changing Dynamics of Musical Activity in Corsica", en Tullia Magrini (ed.), Music and Gender: Perspectives from the Mediterranean: 33-66. Chicago: University of Chicago Press.

Bohlman, Philip V. 2003. "And She Sang a New Song", en Tullia Magrini (ed.), Music and Gender. Perspectives from the Mediterranean: 329-349. Chicago: University of Chicago Press.

Campo, Alberto del y Ana Corpas. 2005. El mayo festero. Ritual y religión en el triunfo de la primavera. Sevilla: Fundación José Manuel Lara.

Canterla González, Juan Francisco. 2012. Coplas, Bailes y Fandangos en los confines de Andalucía (1680-1808). Sevilla: Agencia Andaluza de Instituciones Culturales.

Canterla González, Juan Francisco. 2014. El Fandango de Huelva, 1730-1944. Sevilla: Consulcom.

Caro Baroja, Julio. 1979. La estación de amor. Fiestas populares de mayo a San Juan. Madrid: Taurus.

Citron, Marcia J. 1993. Gender and the Musical Canon. Cambridge: Cambridge University Press.

Cohen, Judith R. 1987. "Ya salió de la Mar": Judeo-Spanish Wedding Songs among Moroccan Jews in Canada", en Ellen Koskoff (ed.), Women and Music in Cross-Cultural Perspective: 55-67. Urbana: University of Illinois Press.

Cook, Susan C. y Judy S. Tsou. 1994. Cecilia reclaimed. Feminist perspectives on gender and music. Urbana: University of Illinois Press.

Eliade, Mircea. 1972. El mito del eterno retorno. Arquetipos y repetición. Madrid: Alianza/Emecé.

Eliade, Mircea. 1974. Tratado de Historia de las religiones. Madrid: Cristiandad.

Evans, Mary. 1997. Introducción al pensamiento feminista contemporáneo. Madrid: Minerva.

Feld, Steven y Keith H. Basso. 1996. "Introduction", en Jane Kepp (ed.), Senses of Place: 3-12. Santa Fe, NM: School of American Research Press.

Frenk Alatorre, Margit. 1978. Estudios sobre lírica antigua. Madrid: Castalia.

García, Francisco José y Herminia Arredondo. 2010. "Danza y tamboril”, en Juan Agudo, Celeste Jiménez, Francisco José García y Herminia Arredondo, Danzas de la provincia de Huelva: 2531. Huelva: Diputación Provincial de Huelva.

García, Francisco José y Herminia Arredondo. 2012. "Danzas de espadas y toques de tamboril en la Sierra y el Andévalo onubenses", en Iván Iglesias, Pedro Roxo y Susana Moreno (coords.), Música e Saberes em Trânsito. Lisboa: Colibri, Instituto de Etnomusicologia/Centro de Estudos em Música e Dança. 
García Fernández, Máximo. 2004. "Celebraciones de Cruces de Mayo durante el Antiguo Régimen en la Castilla Norte", en David González Cruz (ed.), Las cruces de mayo en España. Tradición y ritual festivo: 21-56. Huelva: Universidad de Huelva.

González, Ángel y Eugenio Mele. 1944. La maya, notas para su estudio en España. Madrid: Consejo Superior de Investigaciones Científicas/Instituto Antonio de Nebrija.

Hanna, Judith Lynne. 1988. Dance, Sex and Gender: Signs of Identity, Dominance, Defiance, and Desire. Chicago: University of Chicago Press.

Herdorn, Marcia. 1990. "Biology and Culture: Music, Gender, Power, and Ambiguity", en Marcia Herdorn y Susanne Ziegler (eds.), Music, Gender and Culture: 11-26. Wilhelmshaven: Florian Noetzel Verlag.

Herdorn, Marcia y Susanne Ziegler (eds.) 1990. Music, Gender and Culture. Wilhelmshaven: Florian Noetzel Verlag.

Jiménez de Madariaga, Celeste. 2004. "Las fiestas de las cruces de la provincia de Huelva", en David González Cruz (ed.), Las cruces de mayo en España. Tradición y ritual festivo: 95-116. Huelva: Universidad de Huelva.

Jiménez de Madariaga, Celeste. 2011. "Rituales festivos y confrontación social. Cruces de mayo de la provincia de Huelva". Gazeta de Antropología 27(2): art. 31. Disponible en: <http://hdl.handle.net/10481/ $18640>$.

Koskoff, Ellen (ed.). 1987. Women and Music in Cross-Cultural Perspective. Urbana/Chicago: University of Illinois Press.

Magrini, Tullia (ed.). 2003. Music and Gender. Perspectives from the Mediterranean. Chicago: University of Chicago Press.

McClary, Susan. 1991. Feminine endings. Music, Gender and Sexuality. Minneapolis: University of Minnesota Press.

Moreno Navarro, Isidoro. 1982. "Cofradías andaluzas y fiestas: aspectos socioantropológicos", en Honorio M. Velasco (ed.), Tiempo de fiesta: ensayos antropológicos sobre las fiestas en España: 71-93. Madrid: Tres-Catorce-Diecisiete.

Moreno Navarro, Isidoro. 1985. Cofradias y hermandades andaluzas. Granada: Biblioteca de Cultura Andaluza.

Ortner, Sherry B. 1974. "Is female to male as nature is to culture?", en Michelle Z. Rosaldo y Louise Lamphere (eds.), Woman, culture, and society: 68-87. Stanford: Stanford University Press.

Ortner, Sherry B. y Harriet Whitehead (eds.). 1981. Sexual Meanings. The Cultural Construction of Gender and Sexuality. Cambridge: Cambridge University Press.

Robertson, Carol E. 1987. "Power and Gender in the Musical Experiences of Women", en Ellen Koskoff (ed.), Women and Music in Cross-Cultural Perspective: 225-244. Urbana/Chicago: University of Illinois Press.

Rodríguez Becerra, Salvador. 1999. "Fiestas de mayo en Andalucía. Tradición y cambio en un ritual popular", en Manuel Oliver Narvona (coord.), Antropología de la fiesta. Jornadas de Antropología de las fiestas "Identidad, mercado y poder": 45-56. Elche/Alicante: M\&C Publicidad.

Rodríguez Becerra, Salvador. 2004. "Las cruces de mayo en Andalucía: historia y antropología de una fiesta", en David González Cruz (ed.), Las cruces de mayo en España. Tradición y ritual festivo: 57-80. Huelva: Universidad de Huelva.

Romero Jara, Manuel. 2002. Este es otro cantar. Voces de Alosno-Fandangos de Huelva. Sevilla: Caja Rural del Sur.

Silverman, Carol. 1996. "Music and Power: Gender and Performance among Roma (Gypsies) of Skopje, Macedonia". World of Music 38(1): 63-76.

Silverman, Carol. 2003. "The Gender of the Profession: Music, Dance and Reputation among Balkan Muslim Rom Women", en Tullia Magrini (ed.), Music and Gender: Perspectives from the Mediterranean: 119-146. Chicago: University of Chicago Press.

Solie, Ruth A. (ed.) 1995. Musicology and Difference. Gender and Sexuality in Music Scholarship. Berkeley, LA: University of California Press.

Stokes, Martin. 1994. Ethnicity, Identity and Music: The Musical Construction of Place. Oxford: Berg. Sugarman, Jane C. 1997. Engendering Song. Singing and subjectivity at Prespa Albanian Weddings. Chicago: University of Chicago Press. 
Tolbert, Elizabeth. 1994. "The voice of lament: female vocality and performative efficacy in the FinnishKalerian itkuvirsi, en Leslie C. Dunn y Nancy A. Jones (eds.), Embodied voices. Representing female vocality in western culture: 179-194. Cambridge: Cambridge University Press.

Vázquez León, Antonio. 1997. Ermitas rurales de la provincia de Huelva. Huelva: Diputación de Huelva.

Velasco Má́llo, Honorio M. 1982. "Fiestas de mayo en la tierra de Alcalá", en Honorio M. Velasco (ed.), Tiempo de fiesta: ensayos antropológicos sobre las fiestas en España: 169-203. Madrid: TresCatorce-Diecisiete.

Fecha de recepción: 13 de mayo de 2017

Fecha de aceptación: 26 de octubre de 2017 